\title{
A NUMERICAL SOLUTION OF A SYSTEM OF ORDINARY AND NON-LINEAR PARTIAL DIFFERENTIAL EQUATIONS
}

\section{AUTHORS:

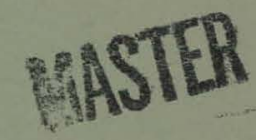

Dale W. Lick

J. Nelson Tunstall

\section{UNION \\ UNION CARRIDE CORPORATION \\ CARBIUE NUCLLAK DIVISION}

Operating the

OAK RIDGE GASEOUS DIFFUSION PLANT OAK RIDGE Y-12 PLANT 


\section{DISCLAIMER}

This report was prepared as an account of work sponsored by an agency of the United States Government. Neither the United States Government nor any agency Thereof, nor any of their employees, makes any warranty, express or implied, or assumes any legal liability or responsibility for the accuracy, completeness, or usefulness of any information, apparatus, product, or process disclosed, or represents that its use would not infringe privately owned rights. Reference herein to any specific commercial product, process, or service by trade name, trademark, manufacturer, or otherwise does not necessarily constitute or imply its endorsement, recommendation, or favoring by the United States Government or any agency thereof. The views and opinions of authors expressed herein do not necessarily state or reflect those of the United States Government or any agency thereof. 


\section{DISCLAIMER}

Portions of this document may be illegible in electronic image products. Images are produced from the best available original document. 
Printed in the United States of America. Available from Clearinghouse for Federal Scientific and Technical Information, National Bureau of Standards,

U.S. Department of Commerce, Springfield, Virginia 22151

Price: Printed Copy $\$ 3.00$; Microfiche $\$ 0.65$

\section{LEGAL NOTICE}

This report was prepared as an account of Government sponsored work. Neither the United States, nor the Commission, nor any person acting on behalf of the Commission:

A. Makes any warranty or representation, expressed or implied, with respect to the accuracy, completeness, or usefulness of the information contained in this report, or that the use of any information, apparatus, method, or process disclosed in this report may not infringe privately owned rights; or

B. Assumes any liabilities with respect to the use of, or for damages resulting from the use of any information, apparatus, method, or process disclosed in this report.

As used in the above, "person acting on behalf of the Commission" includes any employee or contractor of the Commission, or employee of such contractor, to the extent that such employee or contractor of the Commission, or emplayee of such contractor prepares, disseminates, or provides access to, any information pursuant to his employment or contract with the Commission. or his empluyment with such contractor. 
Date of Issue: October 30, 1967

Report Number: $\quad K-1724$

Subject Category: MATHEMATICS

AND

COMPUTERS

A NUMERICAL SOLIUTION OF A SYSTEM

OF ORDINARY AND NON-LINEAR

PARTIAL DIFFERENTIAL EQUATIONS

Dale W. Lick, Consultant

Computing Technology Center

and

J. Nelson Tunstall

Computing Technology Center

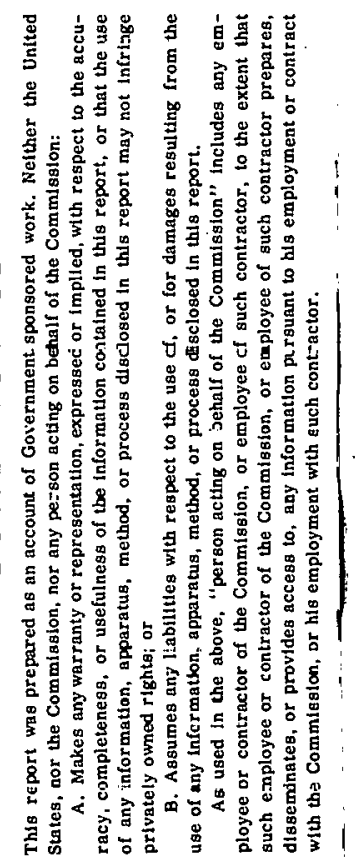

UNION CARBIDE CORPORATION

NUCLEAR DIVISION

Computing Technology Center

Oak Ridge, Tennessee 
THIS PAGE

\section{WAS INTENTIONALLY \\ LEFT BLANK}


TABLE OF CONTENTS

PAGE

Abstract. . . . . . . . . . . . . . . . . 4

1. Introduction. . . . . . . . . . . . . . . 5

2. Statement of the Problem. . . . . . . . . . . . . 7

3. Numerical Methods................. 15

4. Comparison of Numerical Methods . . . . . . . . . . 26

5. Miscellaneous . . . . . . . . . . . . . . 29

Acknowledgment. . . . . . . . . . . . . . 30

References..................... 31

Appendix A. Volumetric Average Reaction Rate . . . . . 32

Appendix B. The Computer Code. . . . . . . . . . . 33 
Abstract

A system of two linear first order ordinary and two non-1inear second order partial differential equations with mixed boundary conditions is considered. Solutions by both linear and non-linear numerical methods are discussed and compared.

The equations arise from a description of the simultaneous chemical reaction and convective-diffusive transport of water vapor and hydrogen through a graphite cylinder. Although specifically written for the steamgraphite system, the equations may have applications to general systems of fluid flow coupled with chemical reactions. 


\section{Introduction}

The chemical reaction between water vapor and carbon,

$$
\mathrm{H}_{2} \mathrm{O}+\mathrm{C} \rightarrow \mathrm{CO}+\mathrm{H}_{2}
$$

is of considerable interest to designers of high-temperature gas cooled nuclear reactors. This interest stems from the widespread use of graphite as fuel cladding and core structural material and the possible presence of water vapor in the coolant either as impurity or through inleakage from the steam generators. Designers consider this "steam-graphite" reaction primarily to determine two quantities:

(1) the magnitude and distribution of the attack on the core graphite under various conditions of water vapor and hydrogen concentrations, flow, and temperature distribution (the attack may deteriorate core structural integrity and may enhance the release of fission products from the fuel), and

(2) the amount of water consumed and hydrogen produced (the hydrogen is a potential explosive hazard and the ratio of hydrogen concentration to water vapor concentration has a controlling influence on the amount of carbon transported from the core and deposited in the heat exchangers).

The determination of these quantities involves making mass balances for hydrogen and water vapor throughout the regions of interest. These mass balances result in a system of four differential equations which, along with their boundary conditions, represent the mathematical model [6] treated in this report. 
We give the mathematical statement of the problem in Section 2 and the linear and non-linear numerical methods employed to solve the problem in Section 3 . The remaining sections are devoted to a discussion and comparison of these numerical methods. Included in the Appendix is a description of a computer program, "Steamcar" written for the IBM $360 / 75$. This program performs the numerical operations needed to solve the system of equations. 


\section{Statement of the Problem}

An inert coolant enters one end and flows turbulently through a cylindrical channel in a long cylindrical piece of graphite that has a non-uniform distribution of temperature. At the channel entrance there is a given constant concentration of water vapor and hydrogen uniformly distributed across the cross section. The exterior boundaries of the graphite cylinder are regions of no flux. Symmetry allows us to express the problem in two-dimensions (see Figure 1).

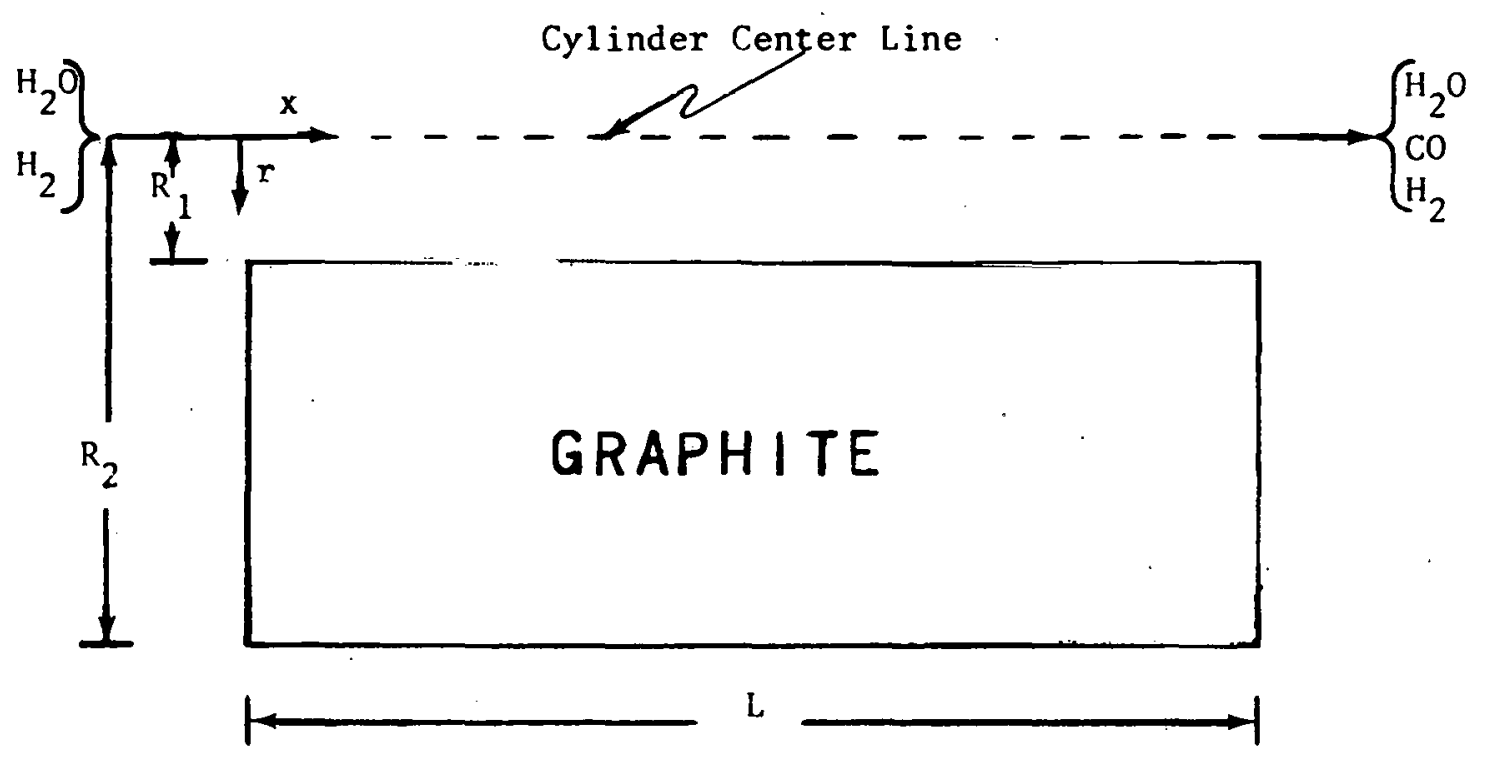

FIGURE I 
We let $u(r, x)$ and $v(r, x)$ denote the concentrations of water vapor and hydrogen at the point $(r, x)$ in the graphite, and let $\bar{u}(x)$ and $\bar{v}(x)$ denote the average concentrations of water vapor and hydrogen in the convecting stream at the point $x$ along the center line of the cylinder.

The transport and rate mechanisms involved are:

(1) turbulent convection through the central coolant channel resulting in mass transfer between the coolant stream and the graphite surface.

(2) permeation throughout the graphite by effective in-pore diffusion, and

(3) the chemical reaction itself.

Steamcar treats these various rate mechanisms as shown separately below.

Turbulent Convection

The water vapor and hydrogen fluxes in the radial direction between the coolant stream and the graphite surface are each expressed by the product of the average concentration potential and a mass transfer coefficient. For water vapor, the flux in the radial direction is given by

$$
\operatorname{flux}_{u, r} \equiv \ell(x)\left[\bar{u}(x)-u\left(R_{1}, x\right)\right],
$$

in which the film coefficient, $\ell(x)$, is obtained from the heat-mass transfer analogy with an arbitrary maximum at the inlet. We, therefore, express $\ell(x)$ by 


$$
\ell(x)=\left\{\begin{array}{l}
(.046) \frac{D_{C}}{2 R_{1}}\left(N_{R e}\right)^{.8}\left(N_{S C}\right)^{.33}, 0 \leq x \leq .2 R_{1}, \\
(.029) \frac{{ }_{C}}{2 R_{1}}\left(\frac{2 R_{1}}{x}\right)^{.2}\left(N_{R e}\right)^{.8}\left(N_{S C}\right)^{.33}, .2 R_{1}<x<x^{*}, \\
(.023) \frac{{ }_{C}}{2 R_{1}}\left(N_{R e}\right)^{.8}\left(N_{S C}\right)^{.33}, x \geq x^{*},
\end{array}\right.
$$

where the value,

$$
x^{*}=2 R_{1}\left(\frac{.029}{.023}\right)^{5} \text {, }
$$

represents the position of "well-developed" flow.

The flux in the axial direction is simply

$$
\operatorname{flux}_{u, x}=\bar{u}(x) ?
$$

where $Q$ is the bulk average coolant velocity.

\section{In-Pore Diffusion}

The flux of water vapor and hydrogen in a given direction within the graphite is expressed by a Fickian type equation. For example, for water vapor traveling in the axial direction,

$$
\operatorname{flux}_{u, x}=-D_{u} \frac{\partial u}{\partial x}
$$

The effective diffusion coefficient, $D_{u}$, is given by [3]

$$
\frac{1}{D_{u}}=\frac{3}{4 K_{0} \nu_{u}}+\frac{1}{\phi D_{c, u}} \text {, }
$$

in which $K_{0}$ and $\phi$ are constants characteristic of the type of graphite, 


$$
v_{u} \equiv \sqrt{\frac{8 R T}{\Pi W_{u}}}
$$

and $D_{c, u}$ is the normal binary molecular diffusion coefficient for water vapor diffusing through the coolant, c. The binary diffusion coefficient is often expressed [1] as

$$
\mathrm{D}_{\mathrm{c}, \mathrm{u}}=\frac{.00185 \mathrm{~T}^{3 / 2}}{\Omega \mathrm{P} \sigma_{\mathrm{u}}^{2}}\left(\frac{1}{\mathrm{~W}}+\frac{1}{\mathrm{~W}_{\mathrm{u}}}\right)^{1 / 2},
$$

where $\mathrm{T}$ is the absolute temperature $\left({ }^{\circ} \mathrm{K}\right)$ and $\mathrm{P}$ is the pressure (atms.), and $W$ and $W_{u}$ are the molecular weights of graphite and water.

In the temperature range of interest (greater than $400^{\circ} \mathrm{C}$ ),

Equation (2.1) is approximated for water vapor and hydrogen by.

$$
D_{u}=\left[\frac{7.317 \times 10^{-5}}{K_{0}} T^{-.5}+\left(8.403 \times 10^{3}\right) \frac{P}{\phi} T^{-1.67}\right]^{-1}
$$

and

$$
D_{v}=\left[\frac{2.187 \times 10^{-4}}{K_{0}} T^{-.5}+\left(1.449 \times 10^{4}\right) \frac{P}{\phi} T^{-1.67}\right]^{-1} \text {. }
$$

Representative values of the graphite constants $[3,4]$ for nuclear grade graphite are

$$
\phi=0.01
$$

and

$$
K_{0}=1.5 \times 10^{-6} \mathrm{~cm} \text {. }
$$

The pressure, $\mathrm{P}$, - is usually in the range 20-100 atmospheres. 
Chemical Reaction

Steamcar uses a comnonly accepted expression for the chemical

reaction rate,

$$
\gamma(u, v)=\frac{K_{1} P_{u}}{1+K_{2} P_{v}+K_{3} P_{u}}
$$

where $\mathrm{P}_{\mathrm{u}}$ and $\mathrm{P}_{v}$ are the partial pressures of water vapor and hydrogen, and

$$
K_{i}=K_{0 i} \exp \left[-E_{i} / R T\right], i=1,2,3,
$$

where $K_{0 i}, E_{i}$, and $R$ are constants.

Using a perfect gas equation of state, Equation (2.2) was expressed in terms of the concentrations rather than the partial pressures,

$$
\gamma(u, v)=\frac{K_{1}(r, x) u(r, x) R_{u} T(r, x)}{1+K_{2}(r, x) v(r, x) R_{v} T(r, x)+K_{3}(r, x) u(r, x) R_{u} T(r, x)} .
$$

Representative values for the reaction constants $[5,7]$ are

$$
\begin{aligned}
& \mathrm{K}_{01}=29.658 \mathrm{gmoles} / \mathrm{g} \text {-min.-atm., } \\
& \mathrm{K}_{02}=0.94185 \times 10^{-10} \mathrm{~atm}^{-1}, \\
& \mathrm{~K}_{03}=0.7062 \times 10^{-15} \mathrm{~atm}^{-1}, \\
& \mathrm{E}_{1}=32.7 \mathrm{Kcal} / \mathrm{gmole}, \\
& \mathrm{E}_{2}=-60.8 \mathrm{Kca} 1 / \text { gmole, } \\
& \mathrm{E}_{3}=-79.3 \mathrm{Kcal} / \mathrm{gmole}, \\
& \mathrm{R}_{\mathrm{u}}=4.615 \times 10^{6} \text { dyne }-\mathrm{cm} / \mathrm{g}-{ }^{\circ} \mathrm{K}, \\
& \mathrm{R}_{\mathrm{v}}=4.124 \times 10^{7} \text { dyne }-\mathrm{cm} / \mathrm{g}-{ }^{\circ} \mathrm{K} .
\end{aligned}
$$




\section{The Mathematical System}

Based on the preceding transfer and rate mechanisms, mass balances can be made in the graphite and the coolant stream [6].

Within the graphite, the mass balance equations for water vapor and hydrogen are

$$
\begin{aligned}
& \frac{\partial^{2} u}{\partial x^{2}}+\frac{\partial^{2} u}{\partial r^{2}}+\frac{1}{r} \frac{\partial u}{\partial r}-\rho \frac{w}{D_{u}} \gamma(u, v)=0, \\
& \frac{\partial^{2} v}{\partial x^{2}}+\frac{\partial^{2} v}{\partial r^{2}}+\frac{1}{r} \frac{\partial v}{\partial r}+\rho \frac{w}{D_{v}} \gamma(u, v)=0,
\end{aligned}
$$

for $0<x<L$ and $\mathrm{P}_{1}<\mathrm{x}<\mathrm{R}_{2}$.

The three boundary conditions representing no flux at the graphite exterior boundaries are

$$
\begin{aligned}
& \frac{\partial u}{\partial r}\left(R_{2}, x\right)=\frac{\partial v}{\partial r}\left(R_{2}, x\right)=0,0<x<L, \\
& \frac{\partial u}{\partial x}(r, 0)=\frac{\partial v}{\partial x}(r, 0)=0, R_{1}<r<R_{2}, \\
& \frac{\partial u}{\partial x}(r, L)=\frac{\partial v}{\partial x}(r, L)=0, R_{1}<r<R_{2} .
\end{aligned}
$$

The boundary values $u\left(R_{1}, x\right)$ and $v\left(R_{1}, x\right), 0<x<L$, are determined from the two equations for the mass balances in the coolant stream,

$$
\begin{aligned}
& \eta \frac{d \bar{u}}{d x}+\frac{2 \ell(x)}{R_{1}}\left[\bar{u}(x)-u\left(R_{1}, x\right)\right]=0,0<x \leq L, \\
& R \frac{d \bar{v}}{d x}+\frac{2 \ell(x)}{R_{1}}\left[\bar{v}(x)-v\left(R_{1}, x\right)\right]=0,0<x \leq L,
\end{aligned}
$$

coupled with the boundary conditions 


$$
\begin{gathered}
\bar{u}(0)=c^{\prime}{ }_{1}, \bar{v}(0)=c^{\prime}{ }_{2}, \\
\left.D_{u} \frac{\partial u}{\partial r}\right|_{R_{1}}+\ell(x)\left[\bar{u}(x)-u\left(R_{1}, x\right)\right], 0<x \leq L, \\
\left.D_{v} \frac{\partial v}{\partial r}\right|_{R_{1}}+\ell(x)\left[\bar{v}(x)-v\left(R_{1}, x\right)\right], 0<x \leq L .
\end{gathered}
$$

Once this system of equations is solved for $u(r, x)$ and $v(r, x)$, the local equilibrium rate of chemical reaction is given by

$$
\rho W Y(u, v) \text {, }
$$

where $\rho$ and $W$ are the density and molecular weight of the graphite (see Appendix A) .

The system of equations, (2.3) through (2.9), represents a mathematical description of the attack of water vapor on a graphite cylinder due to convective-diffusive flow and a chemical reaction. The temperature distribution within the graphite, entering through the last terms on the left sides of the equations in (2.3), affects the system in the manner described earlier under the headings "In-Pore Diffusion" and "The Chemical Reaction". The behavior of this system may strongly depend on the temperature distribution, $T(r, x)$, in these non-1inear terms. The computer program for the solution will allow any continuous function for $T(r, x)$. Hnwever, the analysis of the equations will be for a "test case" using

$$
T(r, x)=1725+111\left(\frac{x}{L}+\frac{r-R_{1}}{R_{2}-R_{1}}\right) .
$$


$-14-$

Other values needed in the "test case" are

$$
\begin{aligned}
& \mathrm{L}=60 \mathrm{~cm} ., \\
& \mathrm{R}_{1}=.635 \mathrm{~cm} . \text {, } \\
& \mathrm{R}_{2}=3.81 \mathrm{~cm} \text {., } \\
& \text { p. }=20.41 \mathrm{~atm} ., \\
& Q=2395 \mathrm{~cm} / \mathrm{sec} . \\
& W_{u}=18.016 \mathrm{~g} / \text { mole }, \\
& w_{v}=2.016 \mathrm{~g} / \mathrm{gmole} \text {, } \\
& W=12.01 \mathrm{~g} / \text { mole } \text {, } \\
& \rho=1.7 \mathrm{~g} / \mathrm{cm}^{3} \text {, } \\
& c_{1}^{\prime}=3.523 \times 10^{-3} \mathrm{~g} / \mathrm{cm}^{3} \text {, } \\
& \mathrm{c}^{\prime}{ }_{2}=0 \text {, } \\
& \mathrm{N}_{\mathrm{Re}}=2.54 \times 10^{4} \text {, } \\
& \mathrm{N}_{\mathrm{SC}}=0.38 \text {, } \\
& D_{c}=.53 \mathrm{~cm} \cdot 2 / \mathrm{sec} .
\end{aligned}
$$




\section{Numerical Methods}

In this section we describe the general iterative methods of solution.

Consider the following point sets:

$$
\begin{aligned}
& S=\left\{(r, x) / R_{1}<r<R_{2}, 0<x<L\right\}, \\
& B_{1}=\left\{(r, x) / x=0, R_{1} \leq r \leq R_{2}\right\}, \\
& B_{2}=\left\{(r, x) / x=L, R_{1} \leq r \leq R_{2}\right\}, \\
& B_{3}=\left\{(r, x) / r=R_{2}, 0 \leq x \leq L\right\}, \\
& B_{4}=\left\{(r, x) / r=R_{1}, 0 \leq x \leq L\right\}, \\
& B_{5}=\{(r, x) / r=0,0 \leq x \leq L\} .
\end{aligned}
$$

The region $G$ of the graphite in Figure 1 can then be expressed as

$$
G=\operatorname{SuB},
$$

where

$$
B=B_{1} \cup B_{2} \cup B_{3} \cup B_{4}
$$

is the boundary of $\mathrm{G}$.

Subdivide $G$ into rectangular regions formed by lines parallel to the line $x=0$ and parallel to the line $r=R_{1}$. The intersection of these lines generates a discrete set $G^{\prime}=S^{\prime} U B^{\prime}$ of points $\left(r_{i}, x_{j}\right)$ in $G$, 
$i=1,2, \ldots, n$ and $j=1,2, \ldots, m$, generating the nodes of our grid, with $x_{1}=0, x_{m}=L, r_{1}=R_{1}$, and $r_{n}=R_{2}$, where the prime denotes the comparable discrete set.

Let

$$
\begin{aligned}
& h_{j}=x_{j+1}-x_{j}, j=1,2, \ldots, m-1, \\
& k_{i}=r_{i+1}-r_{i}, i=1,2, \ldots, n-1, \\
& \hat{h}_{j}=h_{j}+h_{j-1}, j=2,3, \ldots, m-1, \\
& \hat{k}_{i}=k_{i}+k_{i-1}, i=2,3, \ldots, n-1, \\
& \bar{w}_{j}=\bar{w}_{\left(x_{j}\right), w=u \text { or } v, j=1, \ldots, m,} \\
& w_{i, j}=w\left(r_{i}, x_{j}\right), w=u \text { or } v, i=1,2, \ldots, n ; \\
& \quad j=1,2, \ldots, m .
\end{aligned}
$$

The finite difference approximations for the derivatives in Equations

(2.3) (for unequal spacings) are

$$
\begin{aligned}
& \left.\frac{\partial^{2} w}{\partial x^{2}}\right|_{\left(r_{i}, x_{j}\right)} \equiv 2\left[\frac{h_{j} w_{i, j-1}-\hat{h}_{j} w_{i, j}+h_{j-1} w_{i, j+1}}{h_{j-1} h_{j} \hat{h}_{j}}\right], \\
& \left.\frac{\partial^{2} w}{\partial r^{2}}\right|_{\left(r_{i}, x_{j}\right)} \equiv 2\left[\frac{k_{i} w_{i-1, j}-\hat{k}_{i} w_{i, j}+k_{i-1} w_{i+1, j}}{k_{i-1} k_{i} \hat{k}_{i}}\right], \\
& \left.\frac{\partial w}{\partial r}\right|_{\left(r_{i}, x_{j}\right)} \equiv \frac{-k_{i}{ }^{2} w_{i-1, j}+\left(k_{i}{ }^{2}-k_{i-1}^{2}\right) w_{i, j}+k_{i-1}^{2} w_{i+1, j}}{k_{i-1} k_{i} \hat{k}_{i}},
\end{aligned}
$$

where $w=u$ or $v$. 
$-17-$

For each point $\left(\dot{r}_{i}, x_{j}\right) \varepsilon S^{\prime}$, the Equations (2.3) then become

$$
\begin{aligned}
& a_{i, j} u_{i, j}-\left(b_{1} u_{i, j-1}+b_{2} u_{i, j+1}+b_{3} u_{i-1, j}+b_{4} u_{i+1, j}\right) \\
& +c_{1} \gamma\left(u_{i, j}, v_{i, j}\right)=0, \\
& a_{i, j} v_{i, j}-\left(b_{1} v_{i, j-1}+b_{2} v_{i, j+1}+b_{3} v_{i-1, j}+b_{4} v_{i+1, j}\right) \\
& -c_{2} \gamma\left(u_{i, j}, v_{i, j}\right)=0,
\end{aligned}
$$

where

$$
\begin{aligned}
& a_{i, j}=a\left(r_{i}, x_{j}\right)=\frac{2}{h_{j-1} h_{j}}+\frac{4 r_{i}-r_{i-1}-r_{i+1}}{r_{i} k_{i-1} k_{i}}, \\
& b_{1}=b_{1}\left(x_{j}\right)=\frac{2}{h_{j-1} \hat{h}_{j}} \\
& b_{2}=b_{2}\left(x_{j}\right)=\frac{2}{h_{j} \hat{h}_{j}}, \\
& b_{3}=b_{3}\left(r_{i}\right)=\frac{3 r_{i}-r_{i+1}}{r_{i} k_{i-1} \hat{k}_{i}} \\
& b_{4}=b_{4}\left(r_{i}\right)=\frac{3 r_{i}-r_{i-1}}{r_{i} k_{i} \hat{k}_{i}}, \\
& c_{1}=\frac{\rho N_{u}}{n_{u}}
\end{aligned}
$$

and

$$
c_{2}=\frac{\rho w_{v}}{D_{v}}
$$


We approximate the derivatives in Equations (2.4) by

$$
\left.\frac{\partial w}{\partial r}\right|_{\left(r_{i}, x_{j}\right)} \equiv \frac{w_{i, j}-w_{i-1, j}}{k_{i-1}}
$$

and

$$
\left.\frac{\partial w}{\partial x}\right|_{\left(r_{i}, x_{j}\right)} \equiv \frac{w_{i, j}-w_{i, j-1}}{h_{j-1}} .
$$

where $w=u$ or $v$.

The boundary conditions in Equations (2.4) then become

$$
\begin{aligned}
& w_{n, j}=w_{n-1, j}, j=2,3, \ldots, m-1, \\
& w_{i, 1}=w_{i, 2}, i=2,3, \ldots, n-1, \\
& w_{i, m}=w_{i, m-1}, i=2,3, \ldots, n-1,
\end{aligned}
$$

where $w=u$ or $v$.

The derivatives in Equations $(2.5),(2.6),(2.8)$, and (2.9) are approximated by

$$
\begin{aligned}
& \left.\frac{\partial w}{\partial r}\right|_{\left(r_{1}, x_{j}\right)} \equiv \frac{-k_{2}\left(\hat{k}_{2}+k_{1}\right) w_{1, j}+\hat{k}_{2}^{2} w_{2, j}-k_{1}{ }^{2} w_{3, j}}{k_{1} k_{2} \hat{k}_{2}}, \\
& \left.\frac{d \bar{w}}{d x}\right|_{x_{j}} \equiv \frac{\bar{w}_{j}-\bar{w}_{j-1}}{h_{j-1}},
\end{aligned}
$$

where $w=u$ or $v$.

Then, for each point $\left(r_{i}, x_{j}\right)$ in $B^{\prime}{ }_{4} \cup B^{\prime}{ }_{5}$, the Equations $(2.5),(2.6)$, (2.8), and (2.9), coupled in $u$ and $v$, become 


$$
\begin{aligned}
& \left(R_{1} Q+2 \ell\left(x_{j}\right) h_{j-1}\right) \bar{u}_{j}-2 \ell\left(x_{j}\right) h_{j-1} u_{1, j}=R_{1} Q \bar{u}_{j-1}, \\
& k_{1} \hat{k}_{2} \ell\left(x_{j}\right) \bar{u}_{j}-\left[D_{u_{j}}\left(\hat{k}_{2}+k_{1}\right)+k_{1} \hat{k}_{2} \ell\left(x_{j}\right)\right] u_{1, j} \\
& =-\frac{D_{j}}{k_{2}}\left(\hat{k}_{2}^{2} u_{2, j}-k_{1}^{2} u_{3, j}\right),
\end{aligned}
$$

and

$$
\begin{aligned}
& \left(R_{1} Q+2 \ell\left(x_{j}\right) h_{j-1}\right) \bar{v}_{j}-2 \ell\left(x_{j}\right) h_{j-1} v_{1, j}=R_{1} O \bar{v}_{j-1}, \\
& k_{1} \hat{k}_{2} \ell\left(x_{j}\right) \bar{v}_{j}-\left[D_{v_{j}}\left(\hat{k}_{2}+k_{1}\right)+k_{1} \hat{k}_{2} \ell\left(x_{j}\right)\right] v_{1, j} \\
& =-\frac{D_{j}}{k_{2}}\left(\hat{k}_{2}^{2} v_{2}, j-k_{1}^{2} v_{3, j}\right) .
\end{aligned}
$$

These equations furnish the values for $\bar{u}_{j}, \bar{v}_{j}, u_{1, j}$, and $v_{1, j}, j=2$, $\ldots, \mathrm{m}-1$.

The general iterative scheme for this problem is as follows:

Step 0. Determine initial values for $u$ and $v$.

Step 1. Fix $\mathrm{j}=2$.

Step 2. Calculate:

$$
\begin{aligned}
& \alpha_{1}=R_{1} Q+2 \ell\left(x_{j}\right) h_{j-1}, \\
& \beta_{1}=-2 \ell\left(x_{j}\right) h_{j-1}, \\
& \xi_{1}=R_{1} Q \bar{u}_{j-1}, \\
& \alpha_{2}=k_{1} \hat{k}_{2} \ell\left(x_{j}\right),
\end{aligned}
$$




$$
\begin{aligned}
& B_{2}=-\left[D_{u_{j}}\left(\hat{k}_{2}+k_{1}\right)+k_{1} \hat{k}_{2} l\left(x_{j}\right)\right], \\
& \xi_{2}=-\frac{u_{j}}{k_{2}}\left[\hat{k}_{2}^{2} u_{2, j}-k_{1}^{2} u_{3, j}\right] .
\end{aligned}
$$

Step 3. Calculate:

$$
\begin{aligned}
& \bar{u}_{j}=\frac{\xi_{1} \beta_{2}-\xi_{2} \beta_{1}}{\alpha_{1} \beta_{2}-\alpha_{2} \beta_{1}}, \\
& u_{1, j}=\frac{\alpha_{1} \xi_{2}-\alpha_{2} \xi_{1}}{\alpha_{1} \beta_{2}-\alpha_{2} \beta_{1}} .
\end{aligned}
$$

Step 4. Calculate:

$$
\begin{aligned}
& \hat{B}_{2}=-\left[D_{v_{j}}\left(\hat{k}_{2}+k_{1}\right)+k_{1} \hat{k}_{2} \ell\left(x_{j}\right)\right], \\
& \hat{\xi}_{1}=R_{1} Q \bar{v}_{j-1}, \\
& \hat{\xi}_{2}=-\frac{D_{v_{j}}}{k_{2}}\left[\hat{k}_{2}^{2} v_{2, j}-k_{1}^{2} v_{3, j}\right] .
\end{aligned}
$$

Step 5. Calculate:

$$
\begin{aligned}
& \vec{v}_{j}=\frac{\hat{\xi}_{1} \hat{\beta}_{2}-\hat{\xi}_{2} \beta_{1}}{\alpha_{1} \hat{\beta}_{2}-\alpha_{2} \beta_{1}}, \\
& v_{1, j}=\frac{\alpha_{1} \hat{\xi}_{2}-\alpha_{2} \hat{\xi}_{1}}{\alpha_{1} \hat{\beta}_{2}-\alpha_{2} \beta_{1}} .
\end{aligned}
$$

Step 6. Calculate $u_{i, j}$ and $v_{i, j}$ for $i=2, \ldots, n-1$ using method $\mathrm{Q}, \mathrm{N}$ or $\mathrm{L}$ (which are discussed later in this section).

Step 7. Do Steps 2-6 for $\mathrm{j}=3, \ldots, \mathrm{m}-1$.

Step 8. Calculate the new boundary values using Equations (3.2).

Step 9. Test for convergence. 
The remaining portion of this section will be devoted to discussing methods Q, N and L referred to in Step 6. To simplify this discussion, let

$$
\phi(w)=b_{1} w_{i, j-1}^{(k)}+b_{2} w_{i, j+1}^{(k-1)}+b_{3} w_{i-1, j}^{(k)}+b_{4} w_{i+1, j}^{(k-1)},
$$

when $k$ denotes the iteration number.

Method Q

In this method, we consider the first equation in (3.1), take the previous iterate for the value of $v_{i, j}$, treat the equation as a quadratic equation in ${ }{ }_{i, j}$, and solve the resulting equation by the quadratic formula. We then consider the second equation in (3.1), use the newly calculated value for $u_{i, j}$, and solve the resulting quadratic equation in $v_{i, j}$ by the quadratic formula.

The equations for this method are written as follows:

$$
\begin{aligned}
& a_{i, j} u_{i, j}^{(k)}-\phi(u)+c_{1} \gamma\left(u_{i, j}^{(k)}, v_{i, j}^{(k-1)}\right)=0, \\
& a_{i, j} v_{i, j}^{(k)}-\phi(v)-c_{2} \gamma\left(u_{i, j}^{(k)}, v_{i, j}^{(k)}\right)=0 .
\end{aligned}
$$

Equation (3.5) can then be written as

$$
\begin{aligned}
a_{i, j} \hat{K}_{3}\left(u_{i, j}^{(k)}\right)^{2}+ & {\left[a_{i, j}\left(1+\hat{K}_{2} v_{i, j}^{(k-1)}\right)-\hat{K}_{3} \phi(u)+\hat{K}_{1} c_{1}\right] u_{i, j}^{(k)} } \\
& -\left(1+\hat{K}_{2} v_{i, j}^{(k-i)}\right) \phi(u)=0,
\end{aligned}
$$

where

$$
\hat{K}_{1}=K_{1} R_{u}^{T}, \hat{K}_{2}=K_{2} R_{v}^{T} \text {, and } \hat{K}_{3}=K_{3} R_{u} T \text {. }
$$


Let

$$
\begin{aligned}
& \hat{A}=a_{i, j} \hat{K}_{3}, \\
& \hat{B}=a_{i, j}\left(1+\hat{K}_{2} v_{i, j}^{(k-1)}\right)-\hat{K}_{3} \phi(u)+\hat{K}_{1} c_{1}, \\
& \hat{C}=\left(1+\hat{K}_{2} v_{i, j}^{(k-1)}\right) \phi(u) .
\end{aligned}
$$

If $\hat{B}<0$, set

$$
u_{i, j}^{(k)}=\frac{-\hat{B}+\sqrt{\hat{B}^{2}+4 \hat{A} \hat{C}}}{2 \hat{A}} .
$$

If $\hat{B}=0$, then

$$
u_{i, j}^{(k)}=\frac{\sqrt{\hat{A C}}}{\hat{A}} .
$$

If $\hat{B}>0$, then calculate

$$
\hat{u}=\frac{-B-\sqrt{\hat{B}^{2}+4 \hat{A} \hat{C}}}{2 \hat{A}}
$$

and set

$$
u_{i, j}^{(k)}=\frac{-\hat{C}}{\hat{A u}}
$$

Similarly, Equation (3.6) can be written as

$$
\begin{gathered}
a_{i, j} \hat{K}_{2}\left(v_{i, j}^{(k)}\right)^{2}+\left[a_{i ; j}\left(1+\hat{K}_{3} u_{i, j}^{(k)}\right)-\hat{K}_{2} \phi(v)\right] v_{i, j}^{(k)} \\
-\left[\phi(v)\left(1+\hat{K}_{3} u_{i, j}^{(k)}\right)+c_{2} \hat{K}_{1} u_{i, j}^{(k)}\right]=0 .
\end{gathered}
$$

Let

$$
\tilde{A}=a_{i, j} \hat{K}_{2} \text {, }
$$




$$
\begin{aligned}
& \tilde{B}=a_{i, j}\left(1+\hat{K}_{3} u_{i, j}^{(k)}\right)-\hat{K}_{2} \phi(v) \\
& \tilde{C}=\left(1+\hat{K}_{\dot{3}} u_{i, j}^{(k)}\right) \phi(v)+c_{2} \hat{K}_{1} u_{i, j}^{(k)} .
\end{aligned}
$$

If $\tilde{B}<0$, set

$$
v_{i, j}^{(k)}=\frac{-\tilde{B}+\sqrt{\tilde{B}^{2}+4 \tilde{A C}}}{2 \tilde{A}} .
$$

If $\tilde{B}=0$, set

$$
v_{i, j}^{(k)}=\frac{\sqrt{\tilde{A C}}}{\tilde{A}} .
$$

If $\tilde{B}>0$, then calculate

$$
\hat{v}=\frac{-\tilde{B}-\sqrt{\tilde{B}^{2}+4 \tilde{A C}}}{2 \tilde{A}},
$$

and set

$$
v_{i, j}^{(k)}=\frac{-\tilde{C}}{\bar{A} \hat{v}}
$$

Method N

This method is what might be called a Generalized Newton [2] or a Newton-Gauss-Seidel-Overrelaxation Method. Here we consider the negative of the first equation in (3.1), take the previous iterate for the value of $v_{i, j}$, and treat the resulting equation as a function $F$ of $u_{i, j}$. We obtain a new value of $u_{i, j}$ by subtracting from the present value of $u_{i, j}$ the product of a constant $\omega, 0<\omega<2$, and the quotient of $F\left(u_{i, j}\right)$ and its derivative with respect to $u_{i, j}$. We then consider the negative of the second equation of (3.1), using the newly calculated value for $u_{i, j}$ and treat it as a function $H$ of $v_{i, j}$. We obtain a new value of 
$v_{i, j}$ by subtracting from the present value of $v_{i, j}$ the product of $w$ and the quotient of $H\left(v_{i, j}\right)$ and its derivative with respect to $v_{i, j}$. The equations for this method are written as follows:

$$
\begin{aligned}
& u_{i, j}^{(k)}=u_{i, j}^{(k-1)}-\frac{F\left(u_{i, j}^{(k-1)}\right)}{\frac{\partial \Gamma}{\partial u_{i, j}}\left(u_{i, j}^{(k-1)}\right)}, \\
& v_{i, j}^{(k)}=v_{i, j}^{(k-1)}-\omega \frac{H\left(v_{i, j}^{(k-1)}\right)}{\frac{\partial H}{\partial v_{i, j}}\left(v_{i, j}^{(k-1)}\right)},
\end{aligned}
$$

where

$$
F\left(u_{i, j}^{(k-1)}\right)=-a_{i, j} u_{i, j}^{(k-1)}+\phi(u)-c_{1} \gamma\left(u_{i, j}^{(k-1)}, v_{i, j}^{(k-1)}\right)=0,
$$

and

$$
H\left(v_{i, j}^{(k-1)}\right)=-a_{i, j} v_{i, j}^{(k-1)}+\phi(v)+c_{2} \gamma\left(u_{i, j}^{(k)}, v_{i, j}^{(k-1)}\right)=0
$$

Method L

In this method, we consider the first equation in (3.1), take the previous iterate for the value of $v_{i, j}$ and the previous iterate for the value of $u_{i, j}$ in the denominator of $\gamma$, and solve the resulting equation, which is linear in $u_{i, j}$, for the new value of $u_{i, j}$. We then consider the second equation in (3.1), take the newly calculated value of $u_{i, j}$, and the previous iterate for the value of $v_{i, j}$ in the denominator of $\gamma$, and solve the resulting linear equation in $v_{i, j}$ for the new value of $v_{i, j}$ 
The equations for this method are written as follows:

$$
\begin{gathered}
u_{i, j}^{(k)}=\frac{\phi(u)}{a_{i, j}+f\left(u_{i, j}^{(k-1)}\right)}, \\
v_{i, j}^{(k)}=\frac{1}{a_{i, j}}\left[\phi(v)+c_{2} \gamma\left(u_{i, j}^{(k)}, v_{i, j}^{(k-1)}\right)\right],
\end{gathered}
$$

where

$$
f\left(u_{i, j}^{(k-1)}\right)=\frac{c_{1} \hat{k}_{1}}{1+\hat{k_{2}} v_{i, j}^{(k-1)}+\hat{k}_{3} u_{i, j}^{(k-1)}} .
$$




\section{Comparison of Numerical Methods}

In Section 3 we developed three iterative methods of solution methods $Q, N$ and $L$. We shall now discuss and compare these three methods. Further, we shall discuss two other methods that might seem reasonable for such a problem.

For simplicity let us write our system of partial differential equations in the form

$$
\begin{aligned}
& \nabla^{2} u-\frac{c_{1} u}{1+c_{2} v+c_{3} u}=0, \\
& \nabla^{2} v+\frac{c_{4} u}{1+c_{2} v+c_{3} u}=0 .
\end{aligned}
$$

For different "reasonable" cases, the functions $c_{1}, c_{2}, c_{3}$ and $c_{4}$ range from extremely small to very large numbers. In the "test" case described earlier, these functions take on quite small values. However, a good numerical method should not only solve this "test" case, but should adequately handle the full range of possibilities for the $c_{i}$ 's.

All three methods solved our "test" case very well. On an IBM Model $360 / 75$, methods $L, N$ and $Q$ took, respectively; $1.90,2.43$, and 3.19 minutes to converge.

Method L

For the "test" case, Method L was slightly better than Method $\mathrm{N}$ and approximately twice as fast as Method Q. Similarly, Method L was superior for cases with larger values of the $c_{i}$ 's. Since Method $L$ is so 
easy to apply, is more efficient, and effectively handles the general case for different values of the $c_{i}$ 's, we recommend it over all other methods discussed in this report.

Method N

Although we favor Method L, the Generalized Newton Method has much to recommend it. The algorithm is simple, and, for good initial values, can be expected to effectively solve this type of problem.

\section{Method $Q$}

Method $Q$ works well for small values of the $c_{i}$ 's. However, as these terms get larger, Method $Q$ becomes less efficient. Furthermore, this method is too sensitive; to get accurate results, one must carry. the coefficient of the first degree term in double precision. Although Method $Q$ is satisfactory for certain cases, it is not recommended as the general method of solution for this type of problem.

\section{Other Methods}

When one first considers Equations (4.1), he tends to want to first linearize the non-linear terms in the finite difference equations by using all previous iterates for $u$ and $v$ in these terms. This method of attack is very good for small values of the $c_{i}$ 's. However, as the $c_{i}$ 's get larger and the non-linear terms become more influential, this method fails.

Another approach considered is that of using the quadratic equation of Method $Q$ and linearizing it by replacing one factor of the 
quadratic term by the previous iterate. This method suffers from the same difficulties as the method just above. 
In this section we shall discuss two important concepts relating to this problem. These are overrelaxation and unequal spacings.

\section{Overrelaxation}

In those cases where the $c_{i}$ 's were small, convergence was so rapid that overrelaxation was unnecessary. For the cases with large $c_{i}$ 's, overrelaxation (and underrelaxation) did not appreciably improve convergence.

\section{Unequal Spacings}

In most physical problems of this type, the region of graphite nearest the coolant stream will be more critical and that farthest away of a lesser concern. Therefore, it behooves us, in general, to make the grid much finer near the coolant stream. The unequal spacings we used in our finite difference equations allowed us this flexibility without introducing any real difficulties. 


\section{ACKNOWLEDGMENT}

We would like to acknowledge T. S. Kress for the origination of the problem and assistance in writing this report, and the Nuclear Safety Program in the Reactor Division of the Oak Ridge National Laboratory for the support of the work. 


\section{REFERENCES}

1. Bird, R. B., Stewart, W. E., and Lightfoot, E. N., "Transport Phenomena," John Wiley and Sons, Inc., New York, (1963), p. 511 .

2. Greenspan, D., "Introductory Numerical Analysis of Elliptic Boundary Value Problems," Harper and Row, New York (1965).

3. Hewitt, G. F., "Gaseous Mass Transport Within Graphite," Chemistry and Physics of Carbon (edited by P. L. Walker, Jr.), Marcel Dekker, Inc., New York, Vol. 1 (1965) pp. 94-100.

4. Hewitt, G. F., Moore, M. J. C., and Sharratt, E. W., "The Pcrmeability of Nuclear Grade Graphite to a Variety of Gases," UKAEC Report AERE-R3994, 1966.

5. Johnston, H. F., Chen, C. V., and Scott, D. S., "Kinetics of the Steam-Carbon Reaction in Porous Graphite Tuhes," Industrial and Engineering Chemistry, Vol. 44, No. 7, July 1952, $\overline{\text { pp. }}$ 1564-1569.

6. Kress, T. S., "High Temperature Gas-Cooled Reactor Program Semiannual Progress Report for Period Ending September 30, 1966," USAEC Report ORNL-4036, Oak Ridge National Laboratory, February (1967), pp. 246-248.

7. Woodley, R. E., "A Review of the Reactions of Nuclear Graphite with Oxygen and Water Vapor," HW-75072, September 1962. 
$-32-$

APPENDIX A

VOLUMETRIC AVERAGE REACTION RATE

$\Lambda$ t each point $\left(r_{i} ; x_{j}\right)$ of the grid, a reaction rate, $R_{i, j}$, is calculated from

$$
R_{i, j}=\rho V_{Y}\left(u_{i, j}, v_{i, j}\right)
$$

This reaction rate can be used to obtain a volumetric average reaction rate, $\bar{R}$, for the graphite cylinder by

$$
\bar{R}=\frac{\sum_{i, j=1}^{n-1} R_{i, j}^{m-1} v_{i, j}}{n-1 \sum_{i, j=1}^{m-1} v_{i, j}},
$$

where

$$
v_{i, j}=\pi k_{i} h_{j}\left(r_{i+1}+r_{i}\right)
$$


APPENDIX B

THE COMPUTER CODE

Steamcar is a code, written in Fortran IV for the IBM 360/75, which solves the system of ordinary and non-linear partial differential equations given in Section 2, and utilizes the numerical techniques given in Section 3. The purpose of this section is to describe Steamcar by outlining:

(1) the definitions of the variables used,

(2) the logical flow of the code, and

(3) the input to the code.

A Fortran listing of Steamcar is also included. Whenever possible, the definitions given to variables and routines in Steamcar will be related to the variables used previously in the report.

Definition of Variables in COMMON

The notation $A(I, J)$ indicates that $A$ is an array and the value of A at the $(I, J)$ position corresponds to the value at the point $\left(r_{i}, x_{j}\right)$ in the discrete set $G^{\prime}$ defined in Section 3 .

Blank common contains the following variables:

$A(I, J): \quad$ The water vapor concentration, $u\left(r_{i}, x_{j}\right)$, in the graphite.

$B(I, J): \quad$ The hydrogen concentration, $v\left(r_{i}, x_{j}\right)$, in the graphite.

$\operatorname{ABAR}(J)$ : The water vapor concentration, $\bar{u}\left(x_{j}\right)$, in the coolant stream. 
$\operatorname{BBAR}(J): \quad$ The hydrogen concentration, $\bar{v}\left(x_{j}\right)$, in the coolant stream.

HFX $(J): \quad$ The film coefficient, $\ell\left(x_{j}\right)$.

The following are the labeled commons and the variables they contain:

(a) SLOW:

$$
\begin{aligned}
& \left.\begin{array}{l}
\mathrm{Cl}(\mathrm{I}, \mathrm{J}) \\
\mathrm{C} 2(\mathrm{I}, \mathrm{J}) \\
\mathrm{C} 3(\mathrm{I}, \mathrm{J})
\end{array}\right\}: \begin{array}{l}
\text { The temperature dependent functions } \mathrm{K}_{1}, \mathrm{~K}_{2} \text {, and } \\
\mathrm{K}_{3} \text { in }(2.2) .
\end{array} \\
& \text { DH2O }(I, J): \text { The diffusion coefficient } D_{u}\left(r_{i}, x_{j}\right) \text {. } \\
& \mathrm{DH} 2(\mathrm{I}, J): \text { The diffusion coefficient } \mathrm{D}_{v}\left(\mathbf{r}_{i}, \mathrm{x}_{j}\right) \text {. }
\end{aligned}
$$

(b) MESH:

NX: The number, $m$, of node points in the $x$-direction.

NR: The number, $n$, of node points in the r-direction.

$\operatorname{DELX}(J): \quad$ The value $\mathrm{h}_{j}$.

$\operatorname{DELR}(\mathrm{I}): \quad$ The value $k_{i}$.

RDST(I): The distance $\mathbf{r}_{\mathbf{i}}$.

$\operatorname{DINTX}(J)$ : The value $\hat{\mathrm{h}}_{\mathrm{j}}$.

$\operatorname{DINTR}(\mathrm{J})$ : The value $\hat{k}_{\mathbf{i}}$.

(c) PARMS:

$\left.\begin{array}{l}\mathrm{R} 1 \\ \mathrm{R} 2 \\ \text { GLENTH }\end{array}\right\}$

The graphite cylinder dimensions, $R_{1}, R_{2}$, and $L$.

$\left.\begin{array}{l}\text { C10 } \\ \text { C20 } \\ \text { C30 }\end{array}\right\}$

The constants $\mathrm{K}_{01}, \mathrm{~K}_{02}$, and $\mathrm{K}_{03}$ used in defining $K_{1}, K_{2}$, and $K_{3}$. 


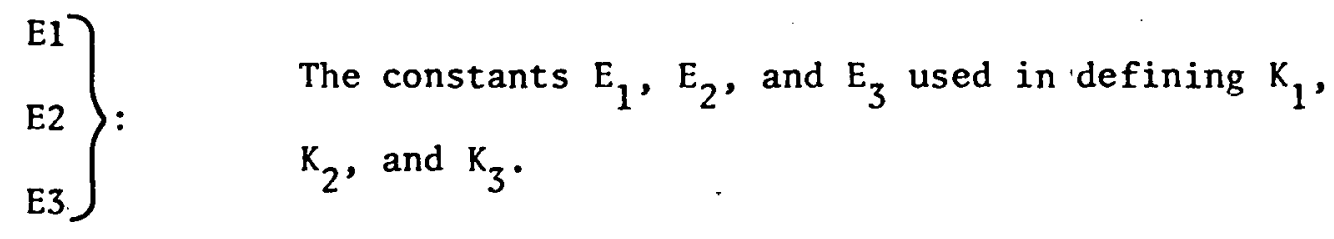

RH20 3 : The constants $\mathrm{R}_{\mathrm{u}}$ and $\mathrm{R}_{v}$ used in the definition of RH2 $\}: \quad r(u, v)$.

RHO: The density $\rho$ of the graphite.

$R$ : The constant $R$ in the definition of $K_{1}, K_{2}$, and $K_{3}$.

$\left.\begin{array}{l}\text { WTA } \\ \text { WTB } \\ \text { WTC }\end{array}\right\}: \quad$ The molecular weights $w_{u}, w_{v}$, and $w$.

UBARX: The bulk average coolant velocity, $Q$.

$\left.\begin{array}{l}\text { REN } \\ \text { SCN } \\ \text { DHE }\end{array}\right\}: \quad \begin{aligned} & \text { The constants } N_{R e}, N_{S C}, \text { and } D_{c} \text { used in the } \\ & \text { definition of } \ell\left(x_{j}\right) .\end{aligned}$

PRESS: The pressure, $P$.

$\left.\begin{array}{l}\text { XKNUD } \\ \text { PSI }\end{array}\right\}: \quad$ The graphite constants $K_{0}$ and $\phi$.

(d) LIMITS:
$\left.\begin{array}{l}\text { NXDIM } \\ \text { NRDIM }\end{array}\right\}: \quad$ The maximum allowable I and $J$ values
MAXCT: The maximum number of iterations the code is to compute.
NPRINT: The values of the ABAR, $A, B B A R$, and $B$ arrays
are printed out every NPRINT iterations.
NRTEST: The convergence tests are made every NRTEST iterations. 


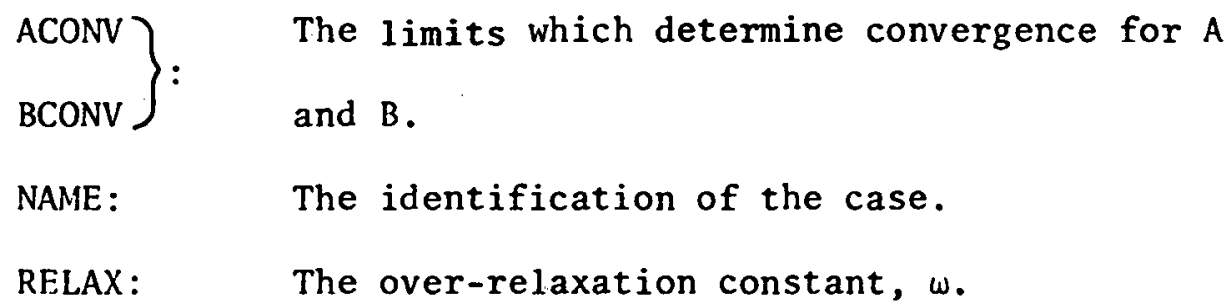

\section{Logical F1ow}

When Steamcar terminates computation on a case, either because convergence with respect to the values of ACONV and BCONV is obtained or because the number of iterations computed exceeds MAXCT, it writes on tape the values of the arrays and parameters for the case. Thus the subroutine INPUTS, depending on the value of the input variable ISTART, either begins a new case from card input of the parameters or restarts a previously calculated case from tape input.

If ISTART $=0$, the case parameters are read from cards, otherwise, the case is extended from tape.

The subroutine MSHSET sets up the discrete set of points $\left(r_{i}, x_{j}\right)$ which define the grid to be used. There are two methods which may be used to determine these grid points.

(1) The user first divides the graphite length into NSEGX segments and the graphite thickness, (R2-R1), into NSEGR segments For each axial segment, s, s = 1, ..., NSEGX, he specifies the number, $\mathrm{ND}_{s}$, of equal spaced grid intervals, each having length $\mathrm{DEL}_{S}$, in which the segment is to be divided. Similarly, he specifies a ND and DEL for each radial segment. 
(2) The user specifies NSEGX and NSEGR as the number of axial and radial grid intervals, and then specifies the values of $\operatorname{DELX}(J), J=1, \ldots, \operatorname{NSEGX}$, and $\operatorname{DELR}(I), I=1, \ldots, \operatorname{NSEGR}$.

The restrictions that $N X \leq M X D I M$ and $N R \leq N R D I M$ must be met. In Method (1),

$$
\mathrm{NX}=1+\mathrm{ND}_{1}+\mathrm{ND}_{2}+\ldots+\mathrm{ND}_{\mathrm{NSEGX}}
$$

and in Method (2),

$$
\mathrm{NX}=\operatorname{NSEGX}+1
$$

In order that the sum of the DELX's equals GLENTH to machine accuracy, MSHSET calculates the DEL for the last axial segment in Method (1) and recalculates, if necessary, the DELX(NSEGX) in method (2). A similar statement can be made for the radial spacing parameters.

If the input variable IREAD $=0$, MSHSET expects the user to define the grid using Method (1); if IREAD $\neq 0$, MSHSET expects the user to define the grid using method (2).

The subroutine HSETUP calculates the film coefficient function HFX(J). The subroutine ESTIMT furnishes initial estimates for the water vapor and hydrogen concentration arrays, and is furnished by the user. The subroutine CDSET sets up the $\mathrm{Cl}, \mathrm{C} 2, \mathrm{C} 3, \mathrm{DH} 20$, and $\mathrm{DH} 2$ arrays and calls the function subprogram TEMP for the value of the temperature at each point. TEMP is furnished by the user.

The subroutine PRINT prints the case parameters and, depending on the value of the input variable ICODE, prints the grid spacing, $\operatorname{HFX}(J)$, and temperature dependent arrays. 


$$
\begin{array}{ll}
\text { ICODE }=0: & \text { No arrays are printed. } \\
\text { ICODE }=1: & \text { The grid spacing arrays and HFX }(J) \text { are printed. } \\
\text { ICODE }=2: & \text { The arrays printed with ICODE }=1 \text { and the tem- } \\
& \text { perature dependent arrays are printed. }
\end{array}
$$

The subroutine SOLVER calls the routine which solves the system of equations. In the listing below, the routine LIEB2 is the method L discussed in Section 3. LIEB2 also handles the convergence tests, the calling of the output routine, and the calculation of the reaction rate and volumetric average.

The subroutine OUTPUT handles the output of the concentration and the reaction rate arrays. It writes the information needed to restart the case on tape, and returns control to the routine called by SOLVER. The subroutine ARR360 is an "array printer" routine.

The subroutines PGMMSK and ITIME are IBM 360 machine language routines. PGMMSK causes the computer system to allow underflows to occur, and ITIME is a timing routine.

\section{Description of Card Input}

FORMAT

Card A :
II

A4

315

$3 \mathrm{~F} 10.0$

I 1
Variables read

ISTART

NAME

MAXCT, NPRINT, NRTEST

RELAX, ACONV, BCONV

ICODE 


\begin{tabular}{|c|c|c|}
\hline \multirow[t]{3}{*}{ Card B: } & $3 F 10.0$ & $\mathrm{R} 1, \mathrm{R} 2$, GLENTH \\
\hline & $3 F 10.0$ & WTA, WTB, WTC \\
\hline & $2 \mathrm{~F} 10.0$ & RHO, UBARX \\
\hline \multirow[t]{3}{*}{ Card C: } & $3 F 10.0$ & $\mathrm{C} 10, \mathrm{C} 20, \mathrm{C} 30$ \\
\hline & $3 F 10.0$ & $\mathrm{E} 1, \mathrm{E} 2, \mathrm{E} 3$ \\
\hline & $2 F 10.0$ & $\mathrm{RH} 20, \mathrm{RH} 2$ \\
\hline \multirow[t]{2}{*}{ Card D: } & $4 F 10.0$ & $\mathrm{R}, \mathrm{REN}, \mathrm{SCN}, \mathrm{DHE}$ \\
\hline & $3 F 10.0$ & PRESS, XKUND, PSI \\
\hline Card E: & $2 \mathrm{~F} 10.0$ & $\operatorname{ABAR}(1), \operatorname{BBAR}(1)$ \\
\hline \multirow[t]{2}{*}{ Card F: } & II & IREAD \\
\hline & $4 X, 2 I 5$ & NSEGX, NSEGR \\
\hline
\end{tabular}

If $\mathrm{IREAD}=0$, the remaining cards are as follows:

Card $\mathrm{G}_{\mathrm{S}}: \quad \mathrm{Al}$ " $\mathrm{X}$ "

$s=1, \ldots$, NSEGX-1 I4 ND: The number of DELX's in the axial segment $s$.

F10.8 DEL: The value of the ND DELX's in segment $s$.

Card $G_{\text {NSEGX }}$ :

Al

"X"

14

ND: The number of DELX's in the last axial segment. (The DEL for the last segment is calculated.)

\footnotetext{
Card $\mathrm{H}_{t}$ :

A1

$t=1, \ldots$, NSEGR-1 I 4
}

"R"

ND: The number of DELR's in the radial segment $t$. 
F10.8

A1

I4
DEL: The value of the ND DELR's in segment $t$.

\section{Card $\mathrm{H}_{\text {NSEGR }}$ :}

"R"

ND: The number of DELR's in the last radial segment. (The DEL for the last segment is calculated.)

If IREAD $\neq 0$, the remaining cards are as follows (where NSEGX $=N X-1$, NSEGR $=$ NR-1):

Cards G:

$8 \mathrm{~F} 10.8$

Cards H:

$8 \mathrm{~F} 10.8$

Code Listing

The remaining portion of this section consists of a FORTRAN IV listing of Steamcar. 
$C * * *$ STEAM-CAR $* * * *$

$\mathrm{C} *$ MAIN CONTROL CECK ***

CALL PGMMSK $(1,0,0,0)$

CALL INPUTS(ISTART, ICODE)

C * ISTART $=0$ MEANS THIS CASE ORIGINATES FROM CARD INPUT ONLY,

C -GT.O MEANS EXTENSION CF A CASE ON UNIT O.

C ISTART $=-1$ MEANS AN ERRQR CONOITION IN THE INPUT DF UNIT 9. IF( ISTART) $100,10,20$

10 CALL MSHSET(ICK)

IFI ICK.LT.O) GO TO 100

CALL HSETUP

CALL ESTIMT

CALL CDSET

20 CALL PRINT(ICODE)

CALL ITIME (ITMI)

CALL SOLVER

1 CO CALL ITIME( ITMI, ITM2)

$X T M 2=F L O A T(I T M 2) / 6000$ NRITE $(6,8000) \times T M ?$

8000 FORMAT('1EXECUTIIJN TOOK ,F10.5," MINS $/)$ RETURN END

SUBROUT INE INPUTS (ISTART, ICUDE)

$C$ * THIS ROUTINE READS THE CASE PARAMETERS EITHER FROM CARDS

C IIF ISTART IS O) OR FROM LOGICAL UNIT NO. 9 (IF ISTART IS NDT 0$).$ CDAMON/ / A $(70,300), B(70,300), A B A R(300), B B A R(300), H F X(300)$ COMMON/SLOW/C1(70,300),C $2(70,300), C 3(70,300), 0 H ? 0(70,300)$, 1 $\mathrm{DH} 2(70,300)$

CCYMON/MESH/NX, NR, DELX $(300)$, DELR $(70)$, RDST $(70)$, CINTX $(300)$, DINTR $(70)$ CCMMON/ PARMS/R1, R2, GLENTH, C 10, C 20, C 30, E1, E2, E3, RH2D, RH2, RHO, R, WTA, WTB, WTC, UBARX, REN, SCN, DHE, PRESS, XKNUD, PS I

C. IMMON/LIMI TS /NXDIM, NRD IM, MAXCT, NPR INT, NRTEST, I TERND, ACONV, BCONV, NAME, RELAX

I TERNO $=0$

iN XO IM $=300$

NRU IM $=70$

$C * *$ INITIALIZE ARRAYS **

OC $10 \mathrm{~J}=\mathbf{l}, \mathrm{NXOIM}$

$\operatorname{AEAR}(J)=0$.

$\operatorname{BBAR}(J)=0$.

$\operatorname{HFX}(J)=0$.

$\operatorname{DEL} \times(\mathrm{J})=0$ 。

DINTX(J)=0。

DC $10 \mathrm{I}=1$, NROIM

$C I(I, J)=0$.

$C 2(I, J)=0$.

$C 3(I, J)=0$.

$\mathrm{DH} 2 \mathrm{O}(\mathrm{I}, \mathrm{J})=0$.

$\mathrm{DH} \geq(\mathrm{I}, \mathrm{J})=0$.

$A(I, J)=0$.

$10 B(I, J)=0$.

DO $201=1$, NRDIM

$D E L R(I)=0$.

REST (I) $=0$.

DINTR (I) $=0$

30 CONTINUE 
$\mathrm{C}$

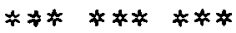

READ $(5,8000)$ I START, NAME, MAXCT, NPR INT, NRTEST, PELAX, ACONV, BCQNV,

8000 FORMAT(I $1, A 4,3$ I 5,3 F 10.0, I 1$)$

IF(ISTART.EQ.0) GO TO 40

REN IND 9

READ( S)NMCK, R1, R2, GLENTH,C10, C2O,C3O, E1, E2, EZ, RH2O, RH2, RHD,$$
1
$$

2

$R, W T A, W T B, W T C, U R A R X, R E N, S C N$, DHE, PRESS, XKNUD, PS I, ITERNO, NX,

IF(NAME.NE.NMCK) GO TO 30

READ( $S)(D E L X(J), D I N T X(J), A B A R(J), B B A R(J), H F X(J), J=1, N X)$,

1 (DELR(I), DINTR(I), RDST (I), I = I, NR)

$\operatorname{READ}(9)((A)(I, J), \bar{B}(I, J), C](I, J), C 2(I, J), C 3(I, J), D H 20(I, J), D H 2(I, J)$,

1 $J=1, N \times), I=1, N K I$

REWIND 9

RETURN

30 WRITE $(6,8010)$ NAME, NMCK

8010 FORMATI' 1 INPUT NAME $=$ ',A4,' AND TAPE NAME = ',A4,' DO NOT FQUAL'/

I'OEND OF RUN'I

REWIND

I START $=-1$

RETURN

40 REAC $(5,8020) R 1, R 2$, GLENTH, WTA, WTB, WTC, RHO, UBARX

8020 FGRMAT $(8 F 10.0)$

READ $(5,8020) C 10, C 20, C 30, E 1, E 2, E 3, R H 20, R H 2$

READ $(5,8020) R, R E N, S C N, D H E, P R E S S, X K N U D, P S I$

READ( 5,80?0) ABAR (1),BBAR (1)

$C *$ CCINVERT C1O, C20, AND C 30 TO DYNE LNITS**

$A T M=1.013 E+6$

$C 10=C 10 /(50 * * A T M)$

$C 20=C 20 / A T M$

$C 30=C 30 / A T M$

RETURN

END

SLBROUT INE MSHSET (ICK)

C *** THIS RUUTINE READS THE MESH SPACING PARAMETERS ANO SETS UP THE

$\mathrm{C}$ ARR AYS DELX, LELR, RDST, DINTX, DINTR. C CMMON/MESH/NX, NR, DELX(300), DELR( 70), RDST ( 7C), DINTX(300), DINTR( 70) C CMMON/PARMS/R1,R2, GLENTH,DUM $1(? 0)$

COMMON/LIMITS/NXDIM, NRDIM, DUM $2(8)$

DATA LCODEX/IHX/,LCODER/IHR/

READ ( 5,8000$)$ IREAD,NSEGX, NSEGR

8000 FCRMAT (I I, 4X, 2I I )

C * IREAD=0 IMPLIES SEGMENTATION INPUT WHEP.E. .

$\mathrm{C}$

$\mathrm{C}$

C NSEGX $=N O$. OF $X$ DIRECTION SEGMENTS EACH WITH AN EQUAL DELTA $X$ NSEGR $=N O$. OF R DIRECTION SEGMENTS EACH WITH AN EQUAL DELTA R

* IREAD . NE. O IMPLIES ALL THE DELTAS ARE FUR.NISHED WHERE ...

NSEGX =ND. OF DELTAS IN THE X-DIRECTION

I $C K=0$

NSEGR=ND。 TF DELTAS IN THF R-DIRECTION

IF(IREAD.NE.O), GO TO 200

$N X=0$

$X D S T=0$.

DO $50 \mathrm{~K}=1$, NSEGX

READ $(5,8010) L C O D E, N D, D E L$

8010 FORMATI AI, I 4,F10.8) 


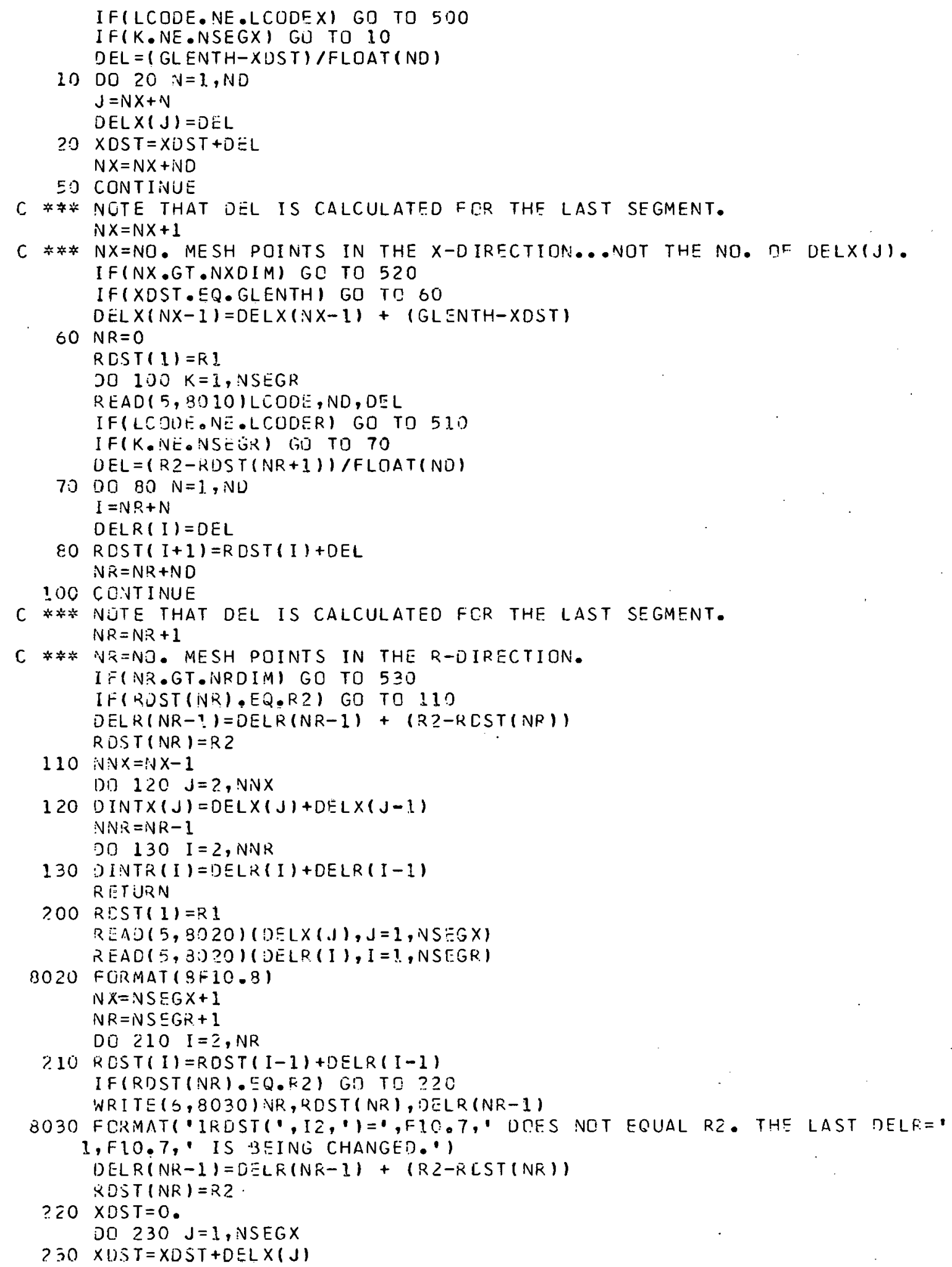




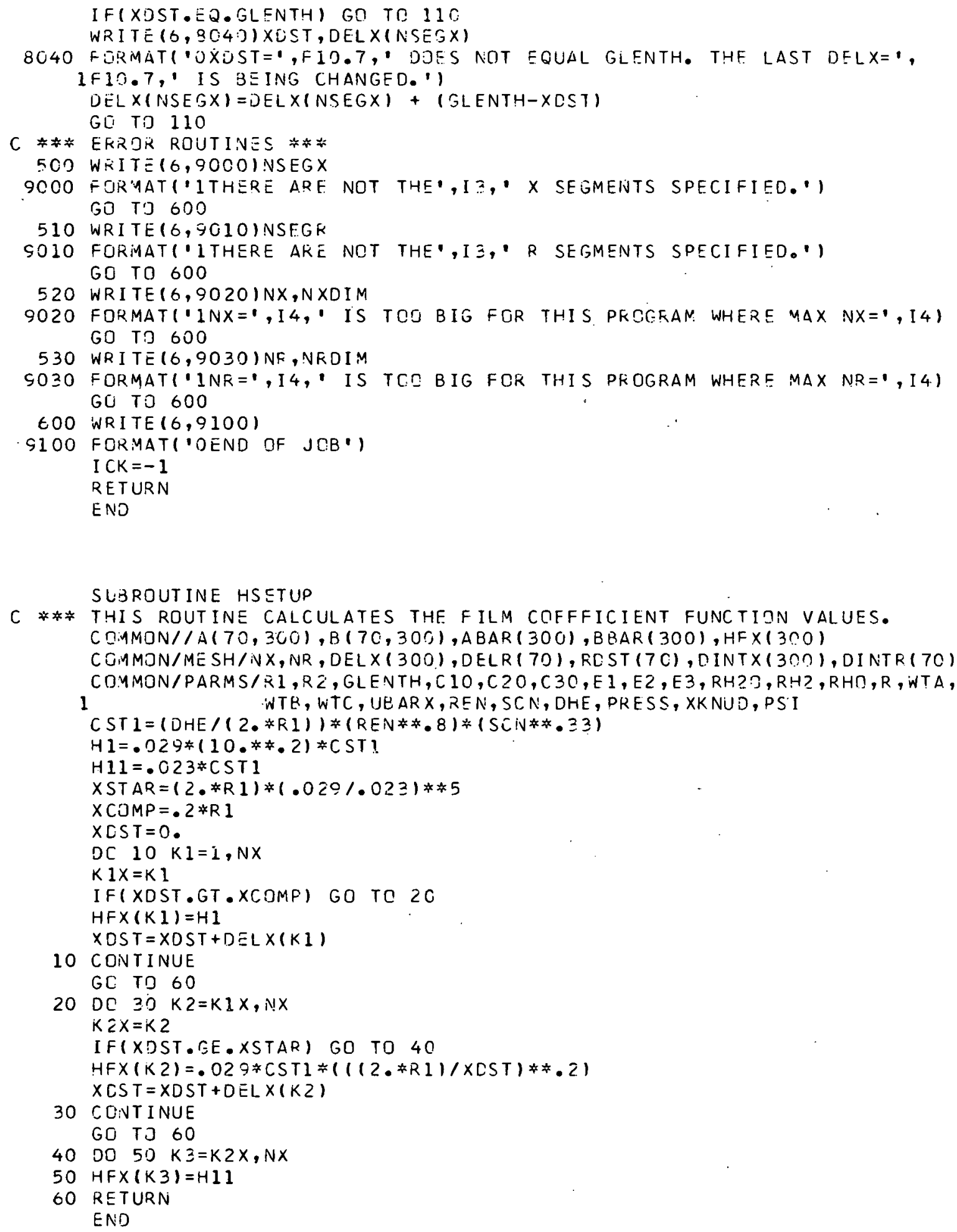


SUZRJUTINE COSET

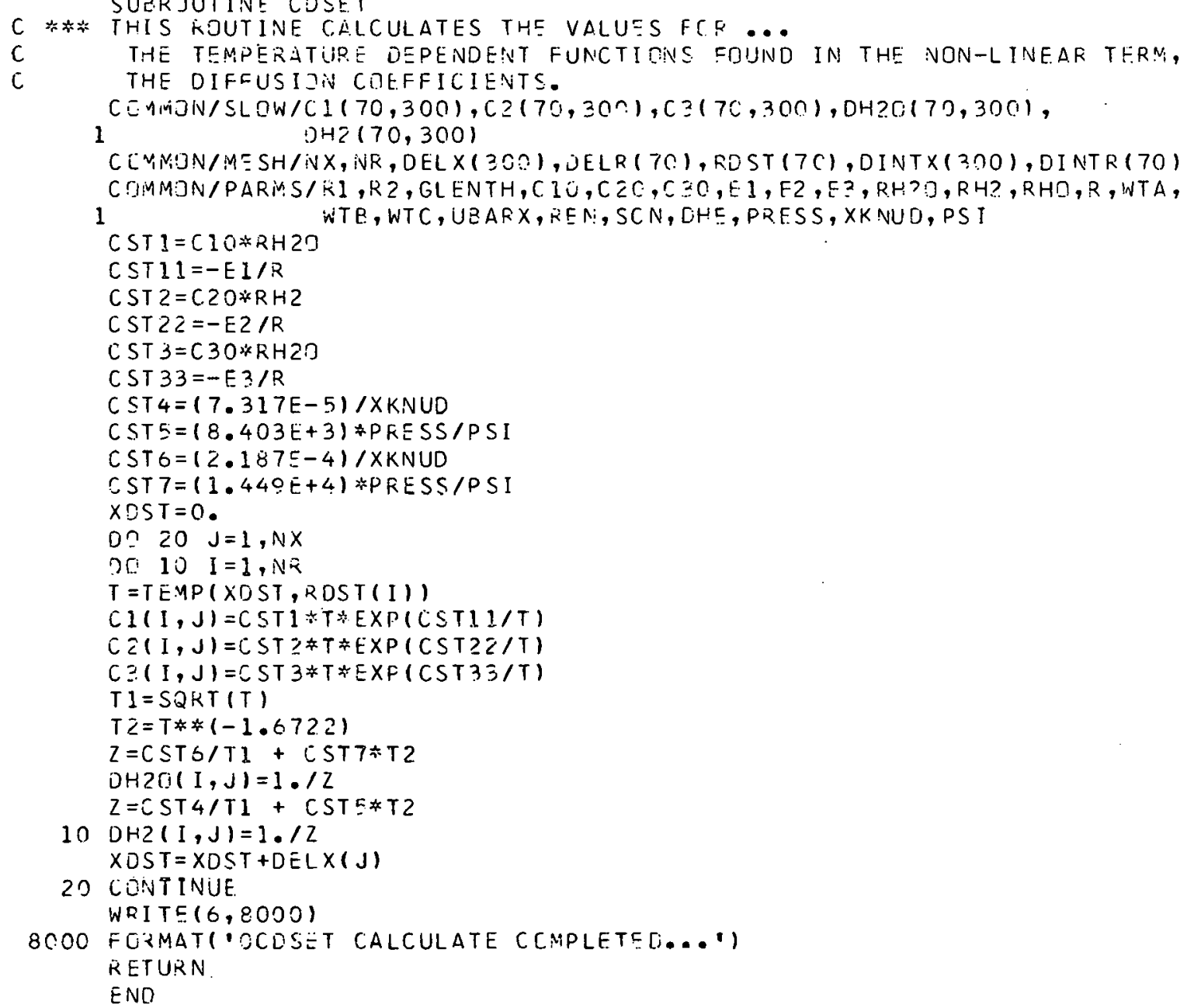

FUNCTION TEMP(XDST, R.DST)

C * THIS FUNCTI JN SUBPROGRAN FUFNISHES THE TEMPERATURE DISTRIBUTICN

C FUNCTIIN FOR THE COUE.

C IT IS SUPPLIED BY THE USER.

CIMMON/ PARMS/RI, R2, GLENTH, C $10, C 20, C 3 C, E 1, E 2, E 3, R H ? O, R H ?, P H D, R$, WTA, 1 WTB, WTC, UBARX, REN, SCN, DHE, PKESS, XKNUD, PS I

$T E M P=1723 .+(111 . / G L E N T H) * X D S T+111 . *(R D S T-F !) /(R ?-F 1)$

RETURN

END

SUBROUTINE ESTIMT

C * THIS ROUTINE FURNISHES INITIAL ESTIMATES IOTHER THAN ZERO.SINCE

C THE ARRAYS ARE ALWAYS INITIALIZED TO ZERO IN INPUTSI.

C IT MUST ÖE WRITTEN BY THE USEF.

COMMJN//A(70,3C0),B(70,300), A RAR( 300$), Q E A R(300), H F X(300)$

C CIMON/MESH/NX, NR, DUMI ( 810$)$ 
$E S T 1=.1 * A B A R(1)$

$M M=N X-1$

DO $10 \mathrm{~J}=2, \mathrm{MM}$

$A(1, J)=E S T$

$1.0 \operatorname{ABAR}(J)=E . S T$

RETURN

END

SLERJUTINE PRINT(ICDOE)

C * THIS RUUTINE PRINTS OUT THE BASIC DARAMETERS fER THE CASE. C CMMJN//A $(70,300), B(70,300), A B A R(\equiv C O), B B A R(\equiv O C), H F X(300)$ COYMON/SLCW/C $1(70,300), C 2(70,300), C 3(70,3 C 0), C H 20(70,300)$,

1 $\mathrm{OH} 2(70,300)$

CCMMEN/MESH/NX, NR, OELX(3)C), DELR( 7C), RCST (70); OINTX(300), DINTR (70) COUMCN/PARMS/FI, R2, GLENTH, C $10, C 20, C \Xi C, E 1, E 2, E \Sigma, R H 20, R H 2, R H G, R$, WTA, 1 WTB, WTC, UBARX, REN , SCN, [HE, PRESS, XKNUD, PS I

C CMMON/L IMI TS/NXOIM, NRDIM, MAXCT, NPR INT, NRTEST, I TERNO, ACONV, BCONV, $1 \quad$ NA.ME, RELAX

$C *$ ICODE $=0$ MIEANS NO ARRAYS ARE PRINTED.

C ILCDE=1 MEANS THE FOLLOWING ARRAYS ARE PRINTED —.

C. DELX,DELR,RDST, DINTX, EINTR, AND HFX.

C ICOLE 2 MEANS ALL ARRAYS ARE PRINTEL. WRITE $(6,8000)$ NAME

8000 FLRMATI 'IGRAPHITE CASE ',A4,' WITH THE FOLLOWING FIXED PARAMETERS. $1 \ldots \cdot 1$

WRITE $(5,8010) R 1, R 2, G L E N T H, C 10, C 20, C \geq C, E 1, E ?, E \equiv, R H 20, R H 2, R H C, R, W T A$, 1 WTB, WTC, UBARX, REN, SCN,DHE, PRESS, XKNUD, PS I

8010 FCRMATI'OR 1 =',F10.5,' R2=',F1C.5,' GLENTH=',F10.5,' C19=', ‥ 15.8 ,

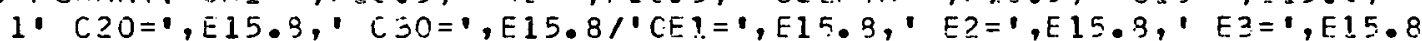
2,' RH2O=', E15.8,'RH2=',E15.8,'RHC=',F10.5,'R=';E15.8/'OWTA=',

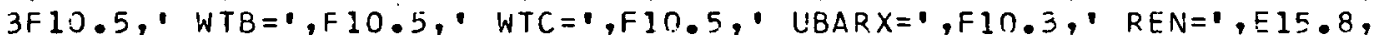

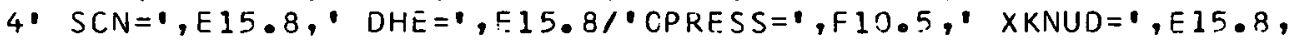
5. $P S I=\cdot, E 15.8)$ WRITE $(6,8020) N R, N X$

8020 FORMAT 'OTHE FIXED GRAPHITE MESH OIMENSIONS ARE..' $/$ ONO. DF ROWS = $1 \cdot, I 4,1 \mathrm{ND}$. OF $\mathrm{COLS}=1, \mathrm{I} 4$ I NRI TE $(6,8030) M A X C T$, NPRINT, I TERNO

8030 FORMATI'DTHIS RUN IS DESIGNATED TE CCMPLETE', IE,' ITERATIONS WITH IMESH PRINT OUTS EVERY ', 15," ITERATIGNS." 'OTHIS CASE HAS PREVICUS 2LY RUN ', IS," ITERATIONS."' WTI TE $(6,8035)$ RELAX, ACONV, BCONV, NRTEST

8035 FDRMAT('OKELAX $=1, F 10.8, \cdot$ ACONV=',E15.7,' BCONV=',F15.7,' NRTEST=', 1141

IF(ICODE.EQ.O) GO TO IDC NRI TE $(5 ; 9040) N X$

SC 40 FURMATI'IOELX $(\mathrm{J}), \mathrm{J}=1$ TO,$I 3)$ WRITE $(6,8045)$ (DELX $X(J), J=1, N X)$

8045 FORMATI IP $8 E 15.5)$ WRITE $(6,9050) N R$

EO50 FORMATI'IOELK(I), I=1 TO ', I ?) WRITE $(5,8045)(D E L F(I), I=1, N R)$ NRITE $(5,8060) \mathrm{NF}$

8CSO FORMAT('ORDST ( 1$), I=1$ TO,$I 2)$ WRITE $(6,8045)($ R.CST $(I), I=1, N R)$ WRITE $(\epsilon, 8070): \mathrm{VX}$

80.76 FRRMAT(1DINTX $(J), J=1$ TO,$(13)$ WRIT $\equiv(5,5045)([\operatorname{INTX}(J), J=1, N X)$ 
WR ITE $(6,8080) \mathrm{NX}$

8080 FORMAT( $1 \mathrm{HF} X(\mathrm{~J}), \mathrm{J}=1$ TO, $\mathrm{I} 3)$

WRITE $(6,8045)(\mathrm{HFX}(\mathrm{J}), \mathrm{J}=1, N X)$

WRITE $(6,8090) N R$

80SO FCRMAT( 1 DINTR(I), I = I TC, , I 2$)$

WRITE $(6,8045)$ (DINTR(I), I =1, NR)

IF(ICODE.EQ.1) FO TO 100

WRITE $(6,9000)$

SOOO FORMAT('1')

CALL ARR360(CI,NR,NX,NROIM, 4H CI)

CALL ARR360(C?,NR,NX,NRUIM,4H C? )

CALL ARR 360 (C3,NR,NX,NROIM, 4H C3)

CALL ARR $360(D H 20, N R, N X, N R D I M, 4 H D H 20)$

CALL ARR $360(0 \mathrm{H} 2, N R, N X, N R D I M, 4 \mathrm{H}$ DH2)

$10 O$ RETURN

END

SUBROUT INE OUTPUT (KKK, I SWT)

CGMMON/ / A $(70,300), B(70,300), A B A R(300), B B A F(300), H F X(300)$

COMMON/SI, NW/C $1(70,300), C ?(70,300), C \equiv(70,300), 0 H 20(70,300)$,

1 $\mathrm{OH} 2(70,300)$

COMMON/MESH/NX,NR, DELX(300), DELR(70), RDST (70), DINTX(300), DINTR(70) COMMON/PARMS/R1, R2, GLENTH, C 10,C ?O,C 30, E1, E2, E3, RH20, RH? , RHD, R, WTA, 1 WTE, WTC, UBARX, REN, SCN, DHE, PRESS, XKNUD, PSI

CGMMCN/L I MI TS /NXDIM, NRD IM, MAXCT, NPRINT, NRTEST, I TERNO, ACONV, BCONV,

1 NAME, RELAX

COMMON/MAX/ARMAX, BRMAX, KKKR

C * ISWT $=0$ MEANS NPRINT TYPE DUTPUT.

C = 1 MEANS CASE CONVERGED.

C

$=2$ MEANS MAX. COLNT WAS EXCEEDED.

$=3$ MIEANS PRINT GRAPHITE CCRROSION RATE.

IF( ISWT.EQ.3) GO TO 100

I TUTI $=K K K+I$ TERNO

$A(1,1)=A(1,2)$

$B(1,1)=B(1,2)$

WRITE $(6,8000)$ ITOT I

8000 FORMATI'IRESULTS AFTER', I5,' ITERATICNS ..'।

WRITE $(6,8010)(A B A R(J), J=1, N X)$

3010 FORMATI OH2O CONCENTRATION IN THE GAS STREAM= $/(1 P 3 E 15.5)$ )

CALL ARR36O (A,NR, NX,NRDIM, 4H H2O)

WRITE $(6,8015)$ ARMAX, KKKR

8015 FCRMAT('JMAX. RESIDUE FOR THE MESH=', EI 5.8,' WHICH WAS CALCULATED

IAT ITERATION ', I 5$)$

WRITE $(5,8020)$ (BBAR.(J), J=1,NX)

8020 FORMAT('IHE CONCENTRATION IN THE GAS STREAM='/(1PQE 15.5))

CALL ARR36O(B,NR, NX,NRDIM, 4H H2,

WRI TE $(6,8015)$ BRMAX, KKKR

IF(ISWT.EQ.O) RLTURP

$C * * *$ WRITE RE-START TAPE ***

ITERNO=ITERNO + KKK

REW IND 10

WRITE (10) NAME, R1, R2, GLENTH, C10,C2O,C30, E1,E2, E3, RH2O,

1

2

RH2, RHO, R, WTA, WTB, WT C, UBAR X, REN, SCN, DHE, PRESS, XKNUD, PS I, ITERNO,NX,NR

WRITE $(10)(D E L X(J), D I N T X(J), A B A R(J), B B A R(J), H F X(J), J=1, N X)$,

1 (DELR(I), DINTR (I), RDST (I), I=1,NR)

WRITE $(10)((A(I, J), B(I, J), C 1(I, J), C 2(I, J), C 3(I, J), 0 H 2 D(I, J)$, 


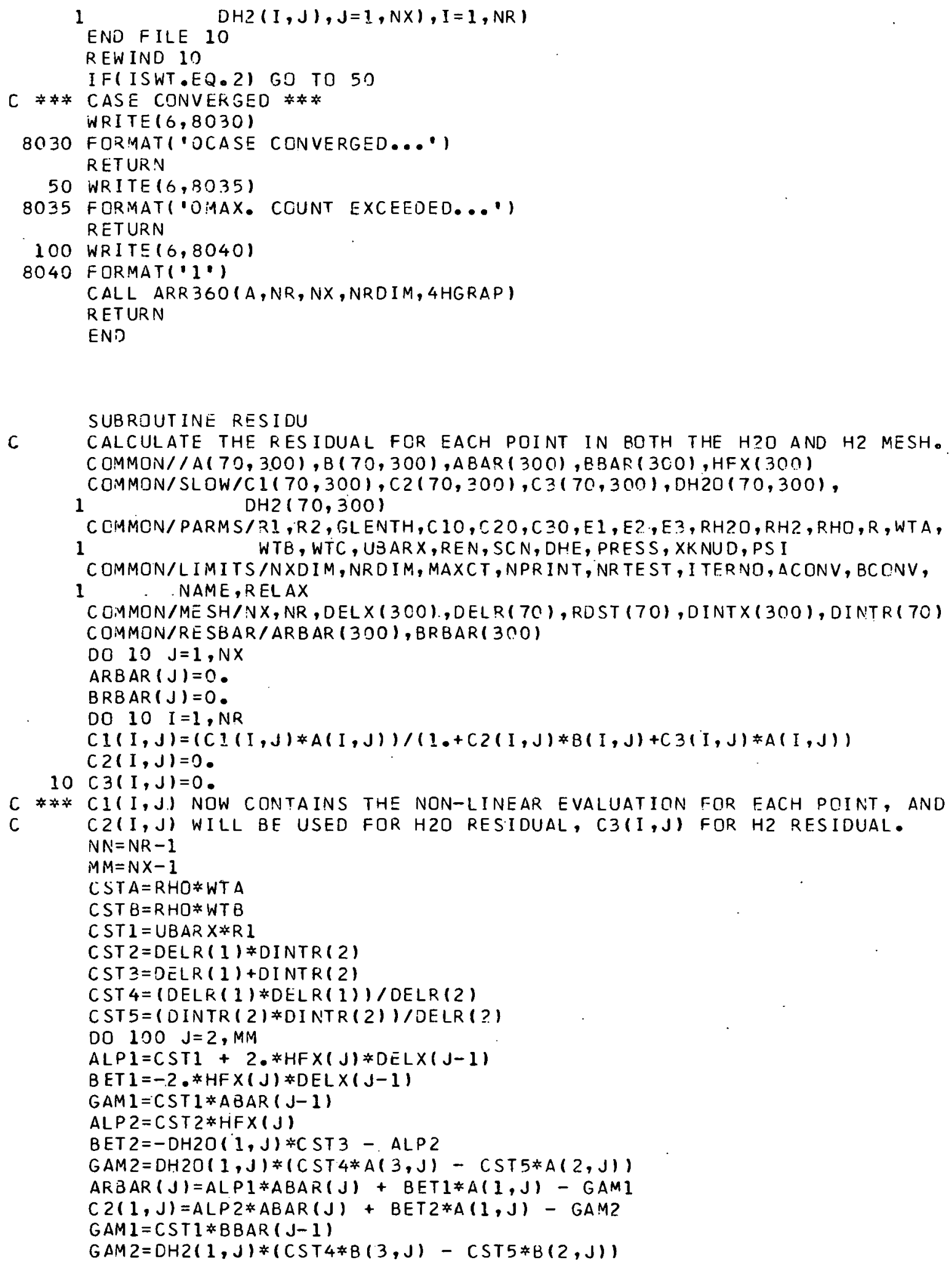




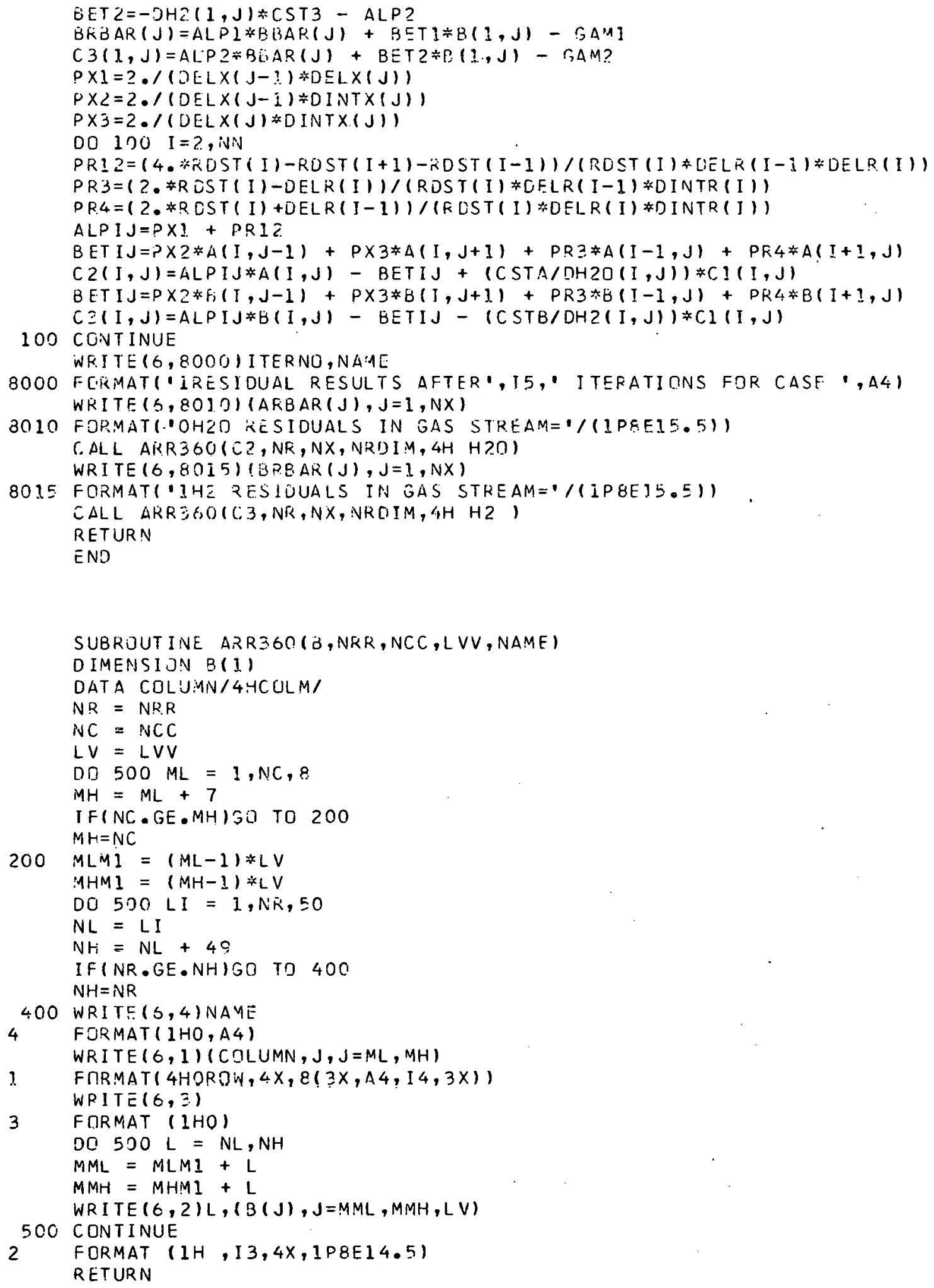


END

SLBROUTINE SOLVER

CALL LIEB?

RETURN

END

SUÖROUTINE LIEE 2

COMMON//A(70,300),B(70,300), ABAR(300), P.BAF(300), HFX(300)

CUMMON/SLOW/C $1(70,300), \mathrm{C} 2(70,300), \mathrm{C} 2(70,300), \mathrm{DH} 20(70,300)$,

1 $\mathrm{DH} 2(70,300)$

C CMMON/MESH/NX, NIR, DELX (300), DELF (70), RDST $(70)$, DINTX $(300)$, DINTP(70) COMMON/PARMS/R1, RZ, GLENTH, C $10, C 20, C 30, F 1, E 2, E 3, R H ? O, R H ?$, RHJ, R, WTA, 1 WTB, WTC, UB $\triangle R X, R E N, \subseteq C N, D H E, P R E S S, X K N U D, P S I$

CEMMON/LIMI TS/NXOIM, NROIM, MAXCT, NPP. INT, NRTEST, I TERNO, ACONV, PCONV, 1 NAME, RELAX COMMON/MAX/ARMAX, BRMAX, KKKR

$C * *$ SET UP CJNSTANTS ***

$M M=N X-1$

$N N=N R-1$

C ST $1=U 3 A R X * R 1$

CST $2=D E L R(1) * D I N T R(2)$

CST $3=D E L R(1)+J I N T R(2)$

OIELR?=UELR(I) UUELR ( 1$)$

D INTK $2=0 I N T R(z) * D I N T R(?)$

C ST $4=$ DELR $2 / D E L R(2)$

CST $5=D I N T R ? / D E L R(2)$

CSTA $=$ RHO*WTA

C * $\quad * * *$ *

D) $2000 \mathrm{KKK}=1, \mathrm{MAXCT}$

DC $100 \mathrm{~J}=2, M: 4$

C ** CALCULATE ELEMENT J OF gAS STREAM AND CF ElW I TF THE GRAPHITE*** $A L P I=C S T I+2 . H F X(J) \neq D E L X(J-1)$

$B E T 1=-2 * H F \times(J) * D E L X(J-1)$

$G A . M 1=C S T 1 * A B A R(J-1)$

$A L P \because=C S T ? * H F \times(J)$

BET? $=-D H 2 O(1, J) * C S T 3-A L P 2$

$G A M Z=D H 2 U(1, J) *(C S T 4 * A(3, J)-\operatorname{CSTS} * A(2, J))$

DENTJIA $=A L P I * B E T Z Z-A L P ? * B E T 1$

AEAR $(J)=($ EAM I*BETZ - GAML*BET 1:IDENCM

$A(1, J)=(A L P 1 * G A H 2$ - $A L D) * G A M I) / D E N O M$

BET $2=-D H 2(1, J) * C S T 3$ - ALP?

DEVOUA $=A L P I * B F T 2-A L P ? * F Z T I$

GAM $1=C S T l \div 3 B A R(J-1)$

$G A M 2=D H 2(I, J) *(C S T 4 * B(3, J)-C S T 5 * B(2, J))$

$B B A Q(J)=(G A M I * B E T 2-G A M ? * B E T 1) / D E N C M$

C

$B(1, J)=(A L P 1 * G A .42-A L P 2 * G A M I) / O E N I M$

$* * * * * * * * * *+*$

$P \times 1=? \cdot /($ JELL $\times(J-1) * J E L \times(J))$

$P \times Z=? . /(0 E L \times(J-I) \div 0 I N T \times(J))$

PX3 $=3 . /(0 \ddot{L} L \times(J) * D I N T \times(J))$

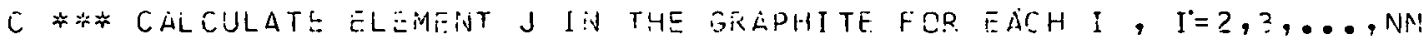

DC IOO I $=$ ?, , NiV

ASAVE $=A(I, J)$ 
$B S A V E=B(I, J)$

PR1 $2=(4 . * \operatorname{RDST}(I)-\operatorname{RDST}(I+1)-\operatorname{RDST}(I-1)) /(\operatorname{RDST}(I) * \operatorname{DELR}(I-1) * \operatorname{DELR}(\mathrm{I}))$ $P R 3=(2 . * R D S T(I)-D E L R(I)) /(R D S T(I) * D E L R(I-I) * D I N T R(I))$

$P R 4=(2 . * \operatorname{RCST}(I)+\operatorname{DELR}(I-1)) /(\operatorname{REST}(\mathrm{I}) * D E L R(I) * D I N T R(I))$

$A L P I J=P X I+P R 12$

$B E T I J=P \times 2 * A(I, J-1)+P \times 3 * A(I, J+1)+P R 3 * A(I-1, J)+P R 4 * A(I+I, J)$

$C 2 B=1$

$F C T=(C S T A * C I(I, J)) /(D H 2 D(I, J) *(C 2 B+C .3(I, I) * A S A V E))$

$A V A L U E=B E T I J /(A L P I J+F C T)$

$A(I, J)=A S A V E+$ F.ELAX* (AVALUE - ASAVE $)$

$B E T I J=P \times 2 * B(I, J-1)+P X 3 * B(I, J+1)+P R 3 * B(I-1, J)+P R * B(I+I, J)$

$G C T=(C S T B * C 1(I, J) * A(I, J)) /(D H 2(I, J) *(C 2 B+C 3(I, J) * A(I, J))$

$B V A L U E=(B E T I J+G C T) / A L P I J$

$B(I, J)=B S A V E+R E L A X *(B V A L U E$ - BSAVE)

100 CONTINUE

$C \neq \neq \neq$ APPLY THE NO FLUX BOUNOARY CONDITIONS

$00200 \quad I=2, N N$

$A(1,1)=A(I, 2)$

$B(I, 1)=B(I, 2)$

$A(I, N X)=A(I, M M)$

$B(I, N X)=B(I, M M)$

200 CONTINUE

DO $250 \mathrm{~J}=2$, MM

$A(N R, J)=A(N N, J)$

$B(N R, J)=B(N N, J)$

250 CONT I NUEE

$C *$ END OF ITERATION

I TERM $=K K K$

C * TEST FOR CONVERGENCE EVERY NRTEST ITERATIONS * *

IF(MOD( I TERM, NRTEST)。NE.O) GO TO 300

ARM AX $=0$.

$B R M A X=0$.

$K K K R=I T E R M$

DO $275 \mathrm{~J}=2$, MM

$P X 1=2 . /(D E L X(J-1) * D E L X(J))$

$P \times 2=2 \cdot /(D E L X(J-1) * 0 I N T \times(J))$

$P \times 3=2 . /(D E L X(J) * D$ INTX(J))

DC $275 \quad 1=2, \mathrm{NN}$

$P R 12=(4 . * R D S T(I)-R D S T(I+1)-\operatorname{RDST}(I-1)) /(\operatorname{RDST}(I) * \operatorname{DELR}(I-1) * D E L R(I))$

$P R 3=(2 . * R D S T(I)-D E L R(I)) /(R D S T(I) * D F L R(I-1) * D I N T R(I))$

$P R 4=(2 . * R D S T(I)+D E L R(I-1)) /(R D S T(I) * D E L R(I) \neq D I N T R(I))$

$F C T=(C 1(I, J) * A(I, J)) /(1 *+C 2(I, J) * B(I, J)+C 3(I, J) * A(I, J))$

$A L P I J=P \times I+P R 12$

$B E T A 1=P X 2 * A(T, J-1)+P X 3 * A(I, J+1)+P R 3 * A(I-1, J)+P R 4 * A(I+1, J)$

$B E T A 2=P \times 2 * B(I, J-1)+P \times 3 * B(I, J+1)+P R 3 * B(I-1, J)+P R 4 * B(I+1, J)$

RESA $=A B S(A L P I J * A(I, J)-B E T A I+(C . S T A / D H 2 O(I, J) * F C T)$

RESB $=A B S(A L P I J * B(I, J)-B E T A 2-(C S T B / D H 2(I, J)) * F C . T)$

I F ( RESA.GT • ARMAX) ARMAX $=$ RESA

IF (RESB.GT $B$ BRYAX) BRMAX =RESB

275 CONTINUE

C * ARMAX. IS NOW THE MAX. RESIDUE IN A(I,J) AND BRMAX SAME FOR B(I,J) IF( ARMAX.GT.ACONV) GO TC 300

I F(BRMAX.GT.BCONV) GO Tח 300

CALL OUTPUT (I TERM, I)

GC TO 1100

300 IF (KKK.EQ.MAXCT) GO TO 1000

IF(MOD (KKK, NPRINT) . EQ.O) CALL OUTPUT(KKK,O)

1000 CONT INUE

CALL OUTPUT (MAXCT, 2$)$ 


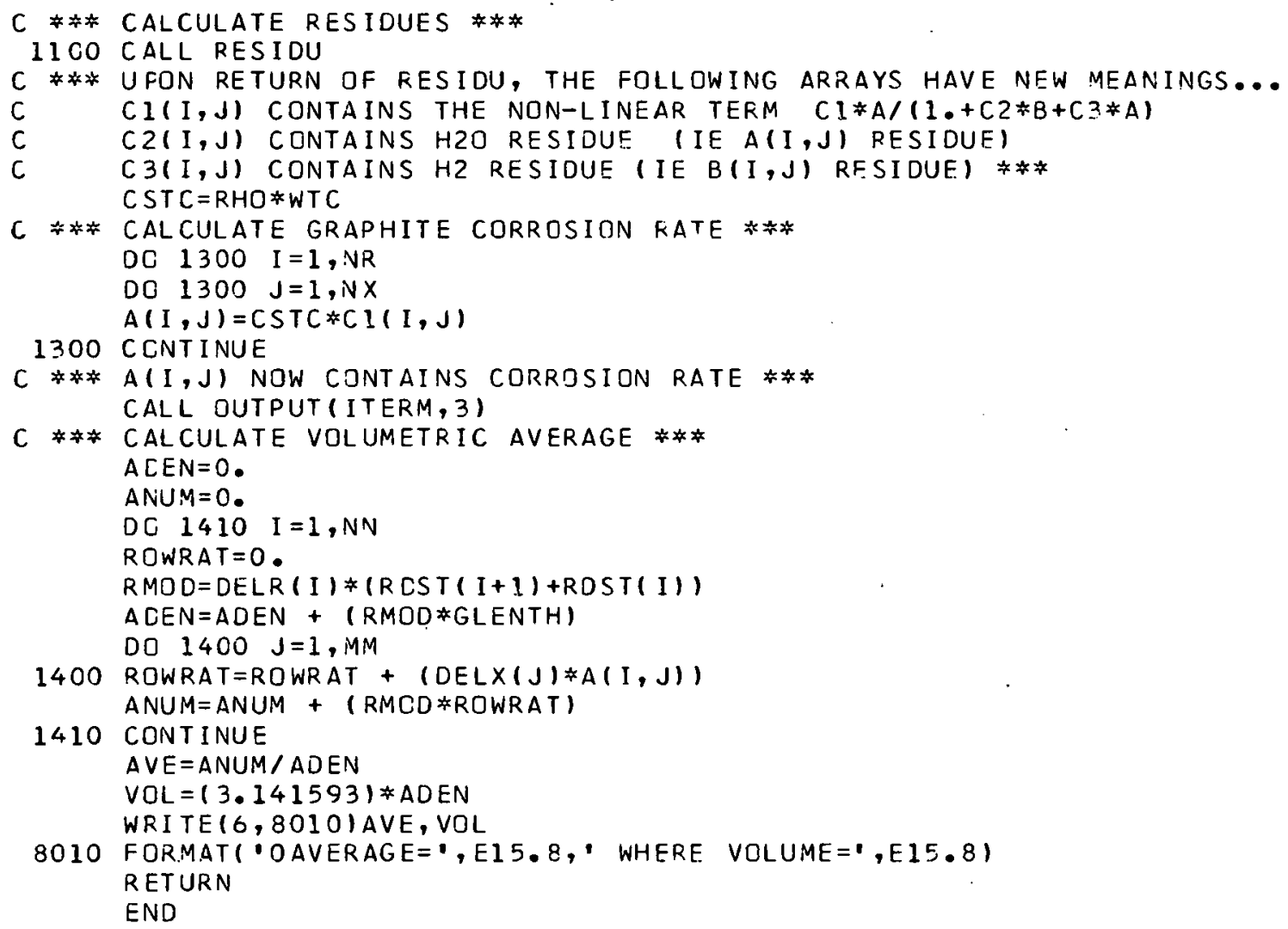

